\title{
Surface Functionalisation of Upconversion Nanoparticles with Different Moieties for Biomedical Applications
}

\author{
Alex Gee ${ }^{1}$ (D) and Xiaoxue $X u^{1,2, *}$ \\ 1 School of Mathematical and Physical Sciences, Faculty of Science, University of Technology, Sydney, \\ NSW 2000, Australia; alex.gee@uts.edu.au \\ 2 Institute of Biomedical Materials and Devices (IBMD), Faculty of Science, University of Technology, Sydney, \\ NSW 2000, Australia \\ * Correspondence: xiaoxuehelen.xu@uts.edu.au; Tel.: +61-430-866-287
}

Received: 14 October 2018; Accepted: 7 November 2018; Published: 11 November 2018

\begin{abstract}
Lanthanide ion-doped upconversion nanoparticles (UCNPs) that can convert low-energy infrared photons into high-energy visible and ultraviolet photons, are becoming highly sought-after for advanced biomedical and biophotonics applications. Their unique luminescent properties enable UCNPs to be applied for diagnosis, including biolabeling, biosensing, bioimaging, and multiple imaging modality, as well as therapeutic treatments including photothermal and photodynamic therapy, bio-reductive chemotherapy and drug delivery. For the employment of the inorganic nanomaterials into biological environments, it is critical to bridge the gap in between nanoparticles and biomolecules via surface modifications and subsequent functionalisation. This work reviews the various ways to surface modify and functionalise UCNPs so as to impart different functional molecular groups to the UCNPs surfaces for a broad range of applications in biomedical areas. We discussed commonly used base functionalities, including carboxyl, amino and thiol moieties that are typically imparted to UCNP surfaces so as to provide further functional capacity.
\end{abstract}

Keywords: upconversion; nanoparticles; lanthanide; surface modification; functionalisation; ligand engineering; silanisation

\section{Introduction}

Extensive research over the past decade has led to an expanded understanding and development of nanomaterials for their considerably broad use across both the scientific and technological spectrums, with disciplines such as nanomedicine, biotechnology, and forensics exhibiting excellent potential for application. Recent advancements have seen the evolution of nanoparticles for their uses in theranostics, including bioimaging, selective therapeutic delivery and biosensing applications where theranostics is a concept that was derived to describe the development of specific, individualised therapies for diseases, whilst merging therapeutic and analytical approaches through multi-modal application [1,2].

The intrinsic photo-physical properties of upconversion nanoparticles make them particularly attractive candidates for diagnostic operations whilst offering the capability to phototherapy. A comprehensive and wide-ranging selection of surface modification methods allows for the specific design of physico-chemical, toxicological, and pharmacological properties, demonstrating their promising versatility across a myriad of practical applications [3-5]. Therefore, the surface modification approaches for UCNPs are selected basically depending on improvements to nanoparticle biocompatibility whilst allowing them to be protected from surrounding aqueous media, thus 
enhancing both the dispersion and denaturation stability of the nanoparticles, preventing their dissolution into ionic species $[4,6,7]$.

Popular choices for the surface modification of UCNPs include molecular ligands or silanisation as they naturally encapsulate and shield the nanoparticles from external interactions, thus substantially minimising nanoparticle dissolution and unwanted exchanges $[5,8]$. Another important role of the surface modified polymer molecules or silica shell is to provide further functionality to the UCNPs for desired operations. Design-enhanced colloidal stability [5,9-17] and bio-conjugation $[2,15,16,18-26]$ are just a few examples from the extensive of significant benefits that can be gained from the functionalisation of UCNPs with functional moieties. There is a small range of common base functional moieties, including carboxyl $(-\mathrm{COOH})$, amino $\left(-\mathrm{NH}_{2}\right)$ and thiol $(-\mathrm{SH})$ groups, but their utilisation across a broad spectrum of applications differs. Environmental influences such as $\mathrm{pH}$, magnetic fields, light, salts, and temperature are manipulated in various ways so as to achieve success through interactions with these functional moieties [27]. Although the moieties can be the same, the desired effect of the external influences may be completely opposing based on the given application.

\section{Surface Modifications}

Commonly synthesised UCNPs are typically capped by surfactant ligands (such as oleate) that aid in the stabilisation of the particles from aggregation. The ligands help to control the growth of the nanoparticles via surface co-ordination while also acting as a solvent during synthesis $[5,28]$. However, these ligands tend to exhibit strong hydrophobic qualities or have minimal functional moieties for further application [3-5,7,29]. Additionally, hydrophilic ligands used in hydrothermal synthesis that co-ordinate via amine or carboxylic groups can be used in the synthesis to impart hydrophilicity but may not supply or allow the modification of necessary functional moieties for desired use [3,5]. Therefore, subsequent modification of UCNPs surfaces allows for specifically tailored or additional physical, chemical or biological attributes, which differ from those originally present on the nanoparticles, to be augmented onto the material surface. This confers changes to hydrophilicity, surface charge and surface energy amongst other properties, for their use in aqueous mediums (specifically in biological systems) [5-7]. Biocompatibility is a significant priority in the design of surface modifications for particles that are intended for use in nanomedical applications, however, a lack of ubiquitous and consistent methodology in the field presents a substantial obstacle along the way to further developments [30]. Moreover, nanoparticles intended for use in biomedical applications require uniformity in morphology and size which presents a greater difficulty in obtaining ideal samples [29].

Various modification strategies exist that have tried to develop universal methods and overcome these limitations but stability in aqueous environments is still a considerable challenge [10]. The four main strategies for surface modification include: (a) ligand engineering [2,3,5,7,9,10,12,31]; (b) layer-bylayer assembly [2,3,5,7,32]; (c) ligand attraction [2,3,5,7,33]; and (d) surface polymerisation [2,3,5,6, 11,13,15-17,34-39]. Each modification method as well as the specific molecules selected, has its own benefits and hindrances. While there are many ways to modify the surfaces of UCNPs, this review aims at covering the two most popular methods, that being ligand engineering and silanisation.

\subsection{Ligand Engineering}

Ligand engineering comprises two methods of surface modification. The first being the oxidation of ligands present on UCNPs surfaces (e.g., oleate) via an oxidiser such as the Lemieux-von Rudloff reagent or ozone. Figure 1 shows a typical ligand oxidation process, which could result in terminal carboxylates, aldehydes or epoxides $[5,17,40]$. The oxidative alteration of ligands is not a commonly used approach to UCNPs surface modification due to the poor dispersal in aqueous media of resultant UCNPs and the limited variability in functional moieties [4,5,29]. Although ligand oxidation exhibits no influence on morphology or size of UCNPs [41,42], work conducted by Naccache, R. et al. (2009) [43] determined that prolonged oxidation ( $>2 \mathrm{~h}$ ) of oleate ligands on $\mathrm{NaGdF}_{4}: \mathrm{Yb}^{3+}, \mathrm{Ho}^{3+} \mathrm{UCNPs}$ resulted in an $\mathrm{MnO}_{2}$ precipitate that was challenging to remove, reduced 
the hydrophilicity of the UCNPs in water and significantly weakened the luminescent emission of the particles. Interestingly, Deng, R. et al. (2011) [42] found that the addition of glutathione (GSH) in low amounts to $\mathrm{MnO}_{2}$-modified $\mathrm{NaYF}_{4}: \mathrm{Yb}^{3+}, \mathrm{Tm}^{3+} \mathrm{UCNPs}$ led to a substantial recovery of emission from the particles. It is asserted that the enhancement of the optical properties was a result of GSH-mediated reduction of $\mathrm{MnO}_{2}$ to $\mathrm{Mn}^{2+}$. Therefore, in the case of prolonged oxidation, it may be possible to remove the $\mathrm{MnO}_{2}$ and recover emission of the particles if necessary.

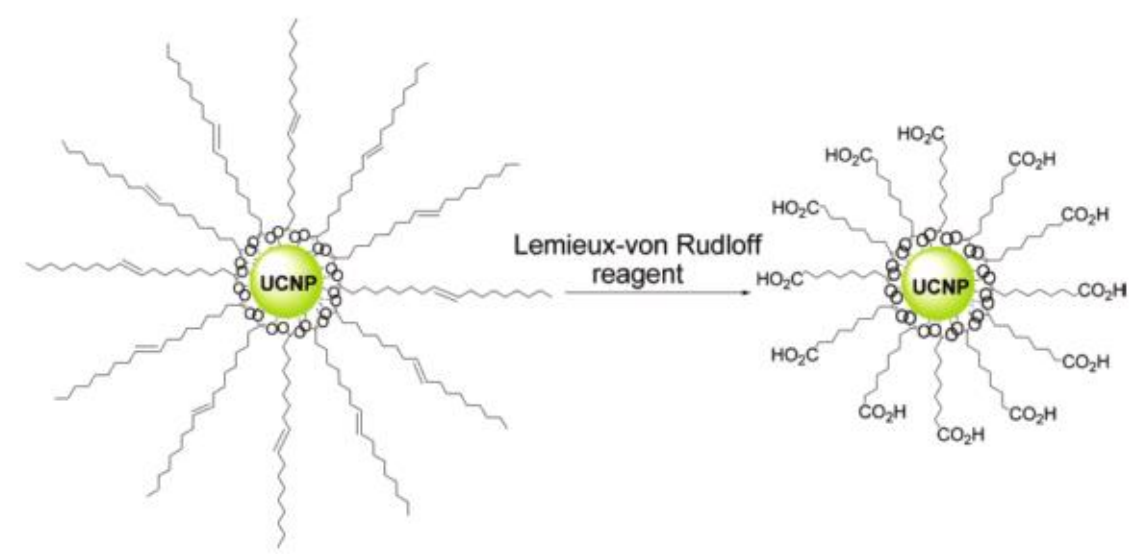

Figure 1. Scheme of the oxidation of oleate with the Lemieux-von Rudloff reagent $\left(\mathrm{MnO}_{4}{ }^{-} / \mathrm{IO}_{4}{ }^{-}\right)$. Note that the dimensions of the NPs and ligands are not to scale. Reprinted with permission from [41]. Copyright 2008 American Chemical Society.

The second method defined under ligand engineering is the ligand exchange process, which is an effective technique to replace hydrophobic ligands on the UCNPs surface with the ligands that exhibit both greater affinity and hydrophilicity. The process is easy to operate, and exhibits a negligible effect on the morphology of the yielded UCNPs. The driving force behind this reaction is that hydrophilic ligand has a stronger coordination ability to lanthanide ions than the original hydrophobic ligand [44]. Figure 2 is the scheme of the ligand exchange process for surface modification of UCNPs. A ligand exchange reaction does not necessarily involve full replacement of all the hydrophobic ligands present on the surface, however, the complete exchange of ligands is ensured if an excess of the new ligand is added to a suitable solvent at elevated temperatures, with the choice of solvent being reliant on the dynamic solvability of both the hydrophobic and new hydrophilic ligands [5].

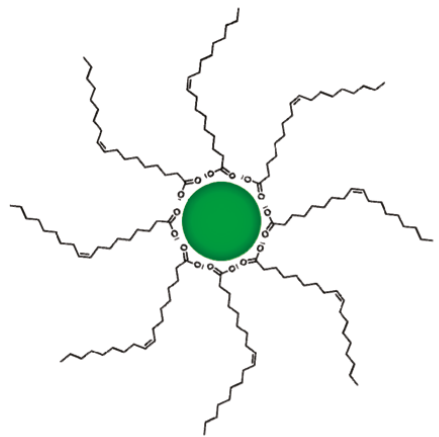

Oleate-coated Upconverting NP

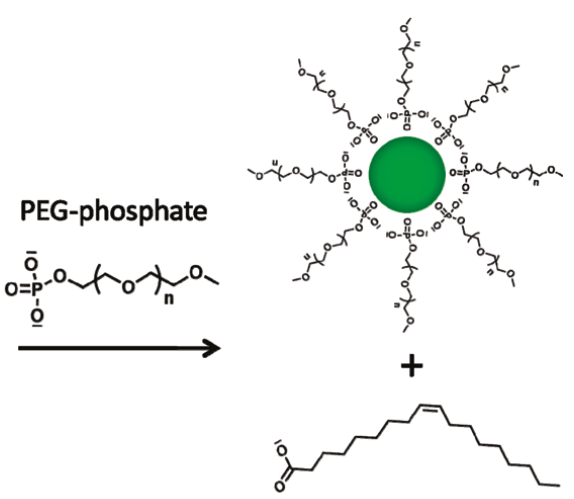

PEG-phosphate-coated Upconverting NP

Figure 2. Schematic illustration of the ligand exchange process where the original oleate capping ligands on the surface of the upconversion nanoparticles are replaced by the PEG-Phosphate ligands. Note that the dimensions of the NPs and ligands are not to scale. Reprinted with permission from [45]. Copyright 2010 American Chemical Society. 
Various hydrophilic ligands have been introduced onto the surfaces of UCNPs via ligand exchange, including ligands such as citrate $[3,5,29]$, hexanedioic acid $[3,5,29]$, polyethylene glycol (PEG) derivatives [5,10,29,31], 6-aminohexanoic acid [3,5,46], polyacrylic acid (PAA) derivatives [10,43,47], and phosphate derivatives $[10,31,48]$. Newly affixed ligands tend to require a certain length in order to be able to provide functionality that can be accessible for subsequent modification but this can be advantageously used in the design of nanoparticle stability. For instance, 1,10-decanedicarboxylic acid (DDA) has been demonstrated to closely crosslink $\mathrm{NaYF}_{4}: \mathrm{Yb}^{3+}, \mathrm{Er}^{3+} \mathrm{UCNPs}$ and $\mathrm{Fe}_{3} \mathrm{O}_{4} \mathrm{NPs}$ via terminal carboxylic acid moieties. Due to the short length of the DDA ligand compared to the oleate ligand, oleate concentration could be optimized so as to functionalise the UCNPs with both oleate and DDA in an advantageous manner via the balance of the ligand exchange progress dynamically. The length of the oleate ligands prevent undesired interactions with anchored carboxylic acid groups present on the shorter DDA ligands by means of steric hindrance, thereby preventing substitution of the crosslinker [49]. Preferably, the newly affixed ligands should be multidentate as the type and number of co-ordination sites on the hydrophobic and hydrophilic ligands strongly influence the efficacy of the exchange. For example, the higher co-ordination displayed by carboxylates makes them a favoured choice over amine-containing ligands, particularly when coating positively-charged UCNPs (i.e., $\mathrm{NaYF}_{4}: \mathrm{Yb}^{3+}, \mathrm{Er}^{3+}$ ) [50].

\subsubsection{Carboxyl Moiety Modified UCNPs via Ligand Engineering}

The exchange of ligands present on as-synthesised UCNPs with ligands exhibiting a carboxylic acid functional moiety would be the most effective method of modification under ligand engineering to impart such functionality. Due to the hydrophilic properties exhibited by carboxyls as well as the ease of coupling between carboxylic moieties and amine residues commonly found on biomolecules, it is a prevalent functionality for bio-sensing applications [41,51-53]. Furthermore, an additional benefit gained by carboxyl functionalisation is the capability to store particles for lengthier periods at an alkaline $\mathrm{pH}$ due to deprotonation of the terminal hydroxyl present on the carboxylic acids. The presence of a formal negative charge gives rise to a larger negative zeta potential and, thus, greater colloidal stability of the sample, substantially reducing agglomeration of the nanoparticles over time [17]. Table 1 summarised the surface modified UCNPs via ligand engineering with carboxyl moieties and their corresponding applications.

Table 1. Summary of surface modified UCNPs via ligand engineering with carboxyl moieties.

\begin{tabular}{|c|c|c|c|c|c|c|}
\hline UCNPs & Ligand & $\begin{array}{l}\text { Coordinating } \\
\text { Moiety }\end{array}$ & $\begin{array}{l}\text { Functional } \\
\text { Moiety }\end{array}$ & $\begin{array}{c}\text { Method of } \\
\text { Functionalisation }\end{array}$ & Application & Ref. \\
\hline $\mathrm{NaYF}_{4}: \mathrm{Yb}^{3+}, \mathrm{Tm}^{3+}$ & DTPA & Carboxylate & $\begin{array}{c}\text { Carboxylic } \\
\text { Acid }\end{array}$ & \multirow[t]{2}{*}{ EDC Chemistry } & $\begin{array}{l}\mathrm{Hg}^{2+} \text { DNA-based } \\
\text { biosensor }\end{array}$ & [51] \\
\hline $\mathrm{NaYF}_{4}: \mathrm{Yb}^{3+}, \mathrm{Tm}^{3+}$ & DPTA & Carboxylate & $\begin{array}{l}\text { Carboxylic } \\
\text { Acid }\end{array}$ & & $\begin{array}{l}\text { DNA-based } \\
\text { biosensor }\end{array}$ & [52] \\
\hline $\mathrm{NaYF}_{4}: \mathrm{Yb}^{3+}, \mathrm{Tm}^{3+}$ & PAA & Carboxylate & $\begin{array}{c}\text { Carboxylic } \\
\text { Acid }\end{array}$ & \multirow[t]{2}{*}{$\begin{array}{l}\text { EDC/NHS } \\
\text { Chemistry }\end{array}$} & $\begin{array}{l}\text { Ligase assisted } \\
\text { DNA-based } \\
\text { biosensor }\end{array}$ & [53] \\
\hline $\begin{array}{c}\mathrm{NaYF}_{4}: \mathrm{Yb}^{3+}, \mathrm{X}^{3+} \\
\left(\mathrm{Ho}^{3+}, \mathrm{Er}^{3+} \text { or } \mathrm{Tm}^{3+}\right)\end{array}$ & AA & Carboxylate & $\begin{array}{l}\text { Carboxylic } \\
\text { Acid }\end{array}$ & & $\begin{array}{l}\text { DNA-based } \\
\text { biosensor }\end{array}$ & [41] \\
\hline $\mathrm{NaYF}_{4}: \mathrm{Yb}^{3+}, \mathrm{Er}^{3+}$ & SOC-Chitosan & Carboxylate & $\begin{array}{c}\text { Carboxylic } \\
\text { Acid }\end{array}$ & \multirow[t]{2}{*}{$\begin{array}{l}\text { Ligand } \\
\text { Exchange }\end{array}$} & $\begin{array}{c}\text { ZnPc-based } \\
\text { photodynamic } \\
\text { Therapy }\end{array}$ & {$[54]$} \\
\hline $\mathrm{NaYF}_{4}: \mathrm{Yb}^{3+}, \mathrm{Er}^{3+}$ & MA-PEG & Carboxylate & Maleimide & & $\begin{array}{l}\text { UCNP-based } \\
\text { platform for } \\
\text { bio-application }\end{array}$ & [55] \\
\hline $\mathrm{NaYF}_{4}: \mathrm{Yb}^{3+}, \mathrm{Er}^{3+}$ & PAA & Carboxylate & $\begin{array}{l}\text { Carboxylic } \\
\text { Acid }\end{array}$ & \multirow{2}{*}{$\begin{array}{l}\text { Electrostatic } \\
\text { Interactions }\end{array}$} & $\begin{array}{l}\text { pH-manipulated } \\
\text { drug delivery }\end{array}$ & [56] \\
\hline $\mathrm{NaGdF}_{4}: \mathrm{Yb}^{3+}, \mathrm{Er}^{3+}$ & Citrate & Carboxylate & $\begin{array}{l}\text { Carboxylic } \\
\text { Acid }\end{array}$ & & $\begin{array}{l}\text { Multifunctional } \\
\text { liposomal } \\
\text { nanocarriers }\end{array}$ & [26] \\
\hline
\end{tabular}


Two representative works published by Kumar and Zhang (2009-2010) [51,52] established the realisation of DNA-based bio-sensors via the modification of $\mathrm{NaYF}_{4}: \mathrm{Yb}^{3+}, \mathrm{Tm}^{3+} \mathrm{UCNP}$ surfaces with diethylenetriaminepentaacetic acid (DTPA). A ligand exchange with oleate allowed for modification of DTPA onto the UCNPs surface whereby exposed carboxyl groups were then coupled to terminus $-\mathrm{NH}_{2}$ groups on ss-DNA via carbodiimide chemistry without the addition of NHS derivatives. Whilst the bio-sensors are similar in concept, they are slightly different in practice. The first sensor [51] relies on ss-DNA that is present on the surface of the UCNPs to convert to a hairpin conformation following interactions with free $\mathrm{Hg}^{2+}$ ions in solution. The change in conformation not only entraps the free $\mathrm{Hg}^{2+}$ ions but an intercalating dye (SYBR Green I) that is also present in solution. When the nanoparticles are excited, their emission is absorbed by SYBRG $(\sim 477 \mathrm{~nm})$ followed by SYBRG emission between 490-520 nm thus indicating entrapment of $\mathrm{Hg}^{2+}$ and the realisation of a DNA-based mercuric ion bio-sensor. The secondary sensor [52] works via the conjugation of complimentary ss-DNA in solution to the ss-DNA present on the UCNPs surface. If complimentary ss-DNA successfully links to the UCNP, the intercalating dye (SYBRG) present in the solution gets trapped between the cross-linked DNA, so when the UCNPs are excited their emission is absorbed by the dye and a subsequent emission at $490-520 \mathrm{~nm}$ is seen. This signals the presence of complimentary DNA, which aims to be correlated to identify diseases, mutagens or pathogens by association.

Using the same carboxy group exposed on the UCNPs surface, further work conducted by Wang and Zhang (2014) [53] determines a ligase-assisted DNA-based bio-sensor by addition of surface carboxyls through ligand exchange of oleate-capped $\mathrm{NaYF}_{4}: \mathrm{Yb}^{3+}, \mathrm{Tm}^{3+}$ with poly(acrylic) acid. Amine-terminated ss-DNA was conjugated to the UCNPs via carbodiimide and NHS chemistry, followed by introduction of an intercalating dye (SYBRG), complementary ss-DNA target ss-DNA into solution. The ss-DNA present on the UCNPs as well as the complementary ss-DNA in solution are matching segments to the target ss-DNA, where a successful match leads to DNA hybridisation followed by ligation, dehybridisation of target DNA and a subsequent hairpin formation between the segments (Figure 3). Ligation of the DNA and subsequent hairpinning would not occur if the segments of ss-DNA were mismatched to the target ss-DNA in solution. As a consequence, this mechanism of action allows for both accurate selectivity and sensitivity regarding determination of target ss-DNA presence. Furthermore, system temperatures during the experiment were manipulated to achieve desired results; this is due to hybridisation occurring at low temperatures and dehybridisation occurring at high temperature, so alteration of temperatures allowed for the acceleration of these processes. Advantageously, the addition of PAA to the surface of the UCNPs allowed for polymeric encapsulation of the nanoparticle cores, which is ideal for the protection from the surrounding aqueous environment, thus prolonging the storage life of the particles.

Although not a typical approach, the oxidation of ligands present on the surface of UCNPs as-synthesised can also be a means of achieving bio-sensing capabilities. Research conducted by Chen et al. (2008) [41] demonstrated the biosensing application of various lanthanide-doped UCNPs $\left(\mathrm{NaYF}_{4}: \mathrm{Yb}^{3+}\right.$ with activator variations of $\mathrm{Er}^{3+}, \mathrm{Ho}^{3+}$ or $\left.\mathrm{Tm}^{3+}\right)$ coated with azelaic acid (AA) ligands. The oleate-capped UCNPs were directly oxidised via addition of the Lemieux-von Rudloff reagent, yielding an exposed terminal carboxylic acid group on the azelaic acid ligands. Addition of the carboxyl moiety imparted both hydrophilicity and bio-conjugation functionality, thus allowing the subsequent cross-linking of streptavidin to the terminal carboxyls via carbodiimide chemistry involving NHS. The streptavidin was further conjugated to capture-DNA that was added to solution with complimentary reporter-DNA attached to a TAMRA quencher. Given that the complimentary reporter-DNA successfully conjugates to the capture-DNA present on the UCNPs, the quencher would then be located in close proximity to the UCNP. This allows for luminescent resonance energy transfer (LRET) to occur as phosphorescence emitted by the UCNP is absorbed by the quencher due to the

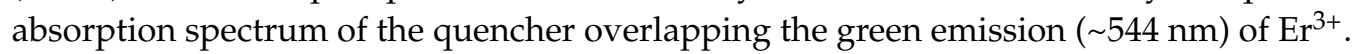




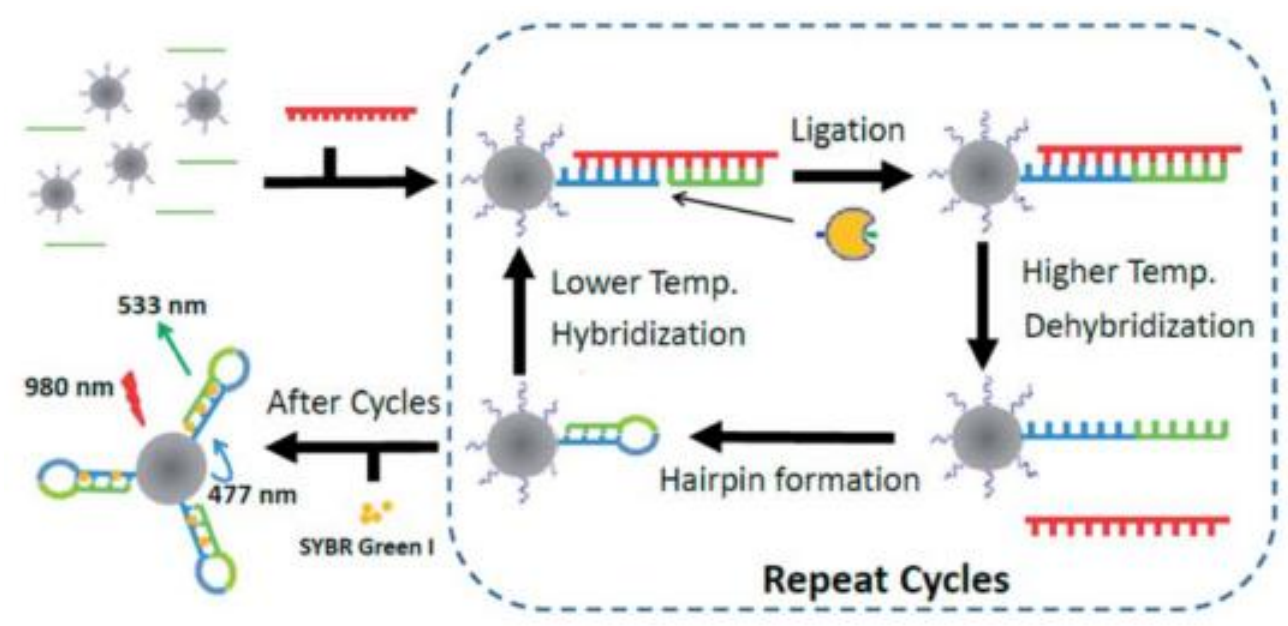

\section{UCNP-DNA_1 UயDNA_2}

Figure 3. Illustration of the ligase-assisted DNA detection scheme based on UCNPs. For DNA match target, ligation occurs and thermal cycling would increase the number of the hairpin structure formed on the UCNP surface. Reprinted with permission from [53]. Copyright 2014 The Royal Society of Chemistry.

The use of carboxyl moieties is not limited to biosensor applications but can also be used for multi-modal theranostic purposes as well, with one possible example being the use of chitosan coated UCNPs for their use in photo-dynamic therapy as demonstrated by Cui et al. [54]. Amphiphilic chitosan (specifically $N$-succinyl- $N^{\prime}$-octyl chitosan) was coated onto $\mathrm{NaYF}_{4}$ : $\mathrm{Yb}^{3+}, \mathrm{Er}^{3+} \mathrm{UCNPs}$ whereby the hydrophobic photosensitiser $\mathrm{ZnPc}$ was loaded into the chitosan. However, due to the amphiphilic nature of the chitosan (SOC), it can be either coated via layer-by-layer attraction (hydrophobic interactions with surface residing oleate alkyl chains) due to exposed octyl groups on SOC or through a ligand exchange via terminal carboxyl groups. Either process would not change the overall mechanism of the application but the latter would be an example of carboxyls being used exclusively for their co-ordination abilities (in the same way oleate coordinates to UCNPs). ZnPc was loaded internally into the SOC via hydrophobic interactions whereby excitation of the UCNPs leads to $660 \mathrm{~nm}$ visible light emission that activates the release of reactive oxygen species (ROS) from activated $\mathrm{ZnPc}$ molecules. The researchers determined a loading capacity of $10.8 \%$, a marked improvement from a comparison where $\mathrm{ZnPc}$ loading in mesoporous silica showed only $\sim 0.1 \%$ loading capacity [57], most likely due to the hydrophilic nature of the silica. Furthermore, induced cell apoptosis was determined in MCF-7 cells as a result of successful ROS release, thereby indicating the successful realisation of an UCNP-based photodynamic therapy system.

Similarly, Liebherr et al. (2012) [55] developed colloidally-stable $\mathrm{NaYF}_{4}$ : $\mathrm{Yb}^{3+}, \mathrm{Er}^{3+} \mathrm{UCNPs}$ via ligand exchange of oleate with maleimide-polyethylene glycol (MA-PEG) that exhibits terminal carboxyl groups. The carboxyl groups were used to coordinate the MA-PEG to the UCNPs, thus resulting in exposed thiol-sensitive maleimide groups that can be used for bioconjugation. Coupling of FITC-labelled $\gamma$-globulin to the UCNPs was accomplished through addition of tris(2-carboxyethyl) phosphine (TCEP), a reduction agent that reduces existing cysteine disulphides present in the $\gamma$-globulin, allowing for thioether bond formation with the exposed maleimide groups. Confirmation of successful coupling was proven via the measuring of fluorescence of the labeled $\gamma$-globulins on both activate and inactive maleimide-functionalised UCNPs whereby active UCNPs demonstrated greater relative red emission while dispersed in water than inactive UCNPs. The reported UCNPs can be utilised as a platform in various bioconjugation applications involving thiols, such as biosensing, bioimaging, and therapeutic delivery. 
The aforementioned examples represent not only the various ways to modify the surface of UCNPs with terminal carboxyls but for the most part, typical applications involving the carboxyl moiety being used for the addition of hydrophilic properties, biomolecule cross-linking capabilities and/or co-ordination capabilities. However, surface moieties can exhibit complex multi-functional properties that can give rise to effective utilisation in various applications. Jia et al. (2013) [56] developed surface modified $\mathrm{NaYF}_{4}: \mathrm{Yb}^{3+}, \mathrm{Er}^{3+} \mathrm{UCNPs}$ with poly(acrylic) acid for their use in a $\mathrm{pH}$-triggered controlled drug delivery system that demonstrates various functionalities of terminal carboxyl groups in practice. At a neutral $\mathrm{pH}$, the anti-cancer drug doxorubicin (DOX) was bound to terminal carboxyl groups residing on the poly(acrylic) acid surface via electrostatic interactions following deprotonation of the carboxyls. As DOX exhibits a positive charge, it becomes tightly bound to the negatively charged carboxyls, leading to the conjugation of DOX molecules surrounding the surface of the UCNPs. Moreover, alteration of $\mathrm{pH}$ conditions can be used to manipulate desired operations; the loading rate of DOX was determined to be high in weakly alkaline environments (approx. $1 \%$ at $\mathrm{pH} 2$, and $32 \%$ at $\mathrm{pH} 7$ ) whilst the rate of release was determined to be high in acidic environments. Further assessment by the group testified to successful drug delivery within in vitro HeLa cells by cytotoxicity assays, where cell viability decreased by $50 \%$. In this case, the carboxyl moieties demonstrate multi-functionality, that being: (1) the capacity to conjugate the anti-cancer drug DOX; (2) the control of the rates of both loading and release via manipulation of environmental $\mathrm{pH}$; (3) imparting hydrophilic properties to the UCNPs so as to increase biocompatibility through surface residing carboxyls; and (4) coordinating poly(acrylic) acid to the UCNPs through internal carboxylate interactions.

Finally, $\mathrm{NaGdF}_{4}: \mathrm{Yb}^{3+}, \mathrm{Er}^{3+} \mathrm{UCNPs}$ were modified to achieve multifunctional upconverting liposomal nanocarriers for their use in anti-cancer drug delivery treatments by Huang et al. (2016) [26] The surface of the UCNPs was modified with citrate ligands which exhibit tri-carboxyl moieties that demonstrate multiple functionalities in practice (as shown in Figure 4). Firstly, deprotonation of the carboxyls leads to subsequent coordination of the citrate ligands to the surface of the UCNPs via a terminal carboxylate moiety. The two remaining surface carboxyl groups then are used to (1) impart hydrophilic properties to the UCNPs; (2) provide a hydrophilic environment for the loading of the anticancer drug DOX; and (3) conjugate as well as stabilise DOX molecules through ionic interactions (carboxylates exhibit a net negative charge whilst DOX exhibits a net positive charge). As DOX has an absorption range overlapping with part of the UCNP emission range ( $515 \mathrm{~nm}-570 \mathrm{~nm}$ ), UV-VIS can be used to quantify the loading capacity of the UCNPs. Following encapsulation of the UCNPs in a liposome made of 1,2-dioleoyl-sn-glycero-3-phosphocholine (DOPC) and cholesterol in a ratio of 2:1, DOX was loaded into Lipo@DOX and UCNP@DOX@Lipo samples. It was determined that the loading efficiency of Lipo@DOX was 98\% whilst UCNP@DOX@Lipo demonstrated a loading efficiency of $72 \%$, the group asserted that this is most likely due to the decreased internal volume of the liposome from UCNPs occupying internal space. Passive drug release of the UCNP@DOX@Lipo particles was tested in both solutions of phosphate buffered saline (PBS) (imitates in vitro conditions) and $50 \%$ foetal bovine serum (FBS) in PBS (imitates in vivo conditions), with passive leaking only accounting for $6 \%$ loss of DOX in PBS over a $12 \mathrm{~h}$ period at $37^{\circ} \mathrm{C}$. As the overall passive release was minimal, PBS can be considered a viable storage solution whilst passive release of 39\% in 50\% FBS + PBS solution indicates the influence of external factors, such as serum protein and lipid bilayer destabilisation interactions that further the complexity of application in vivo. 


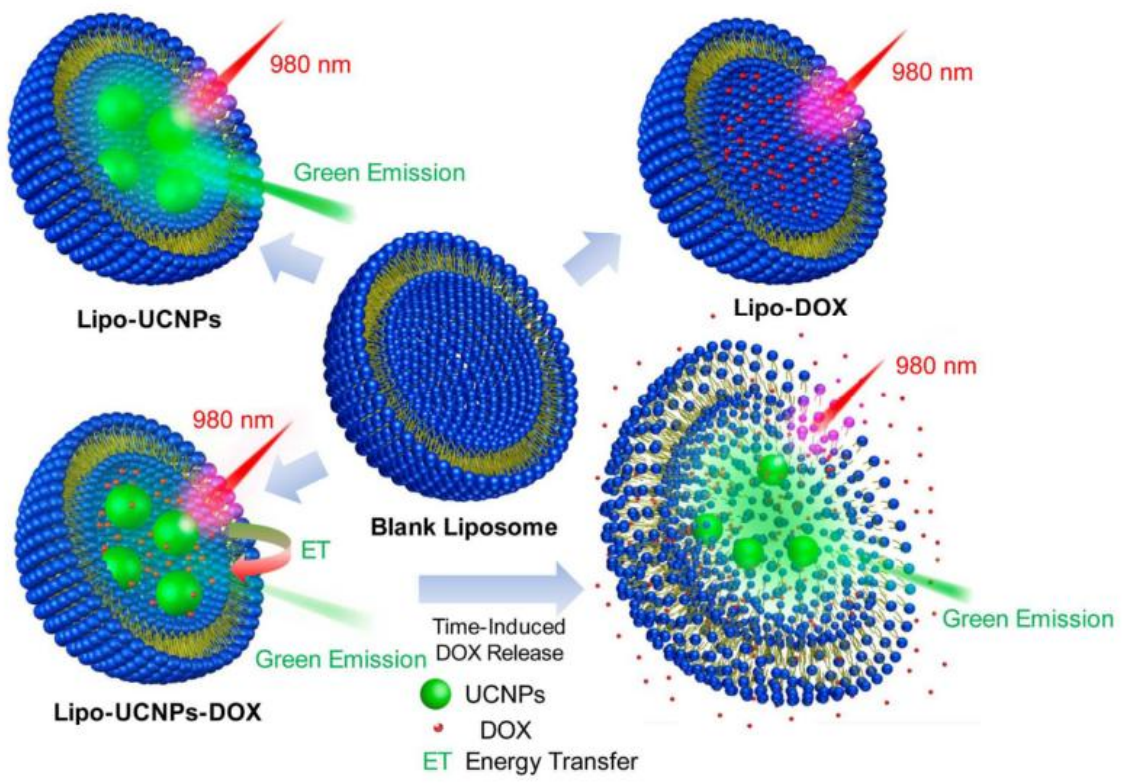

Figure 4. Schematic representation showing the structures of the blank liposome, Lipo-UCNPs, Lipo-DOX, and Lipo-UCNPs-DOX. When UCNPs and DOX were incorporated into the liposome, UCNPs and DOX were located in the inner core of the liposome. Upon laser irradiation ( $980 \mathrm{~nm})$, energy transfer occurred from UCNPs to DOX, where the upconverted green emission is partially absorbed by the DOX. Reprinted with permission from [26]. Copyright 2016 American Chemical Society.

\subsubsection{Amino Moiety Modified UCNPs via Ligand Engineering}

Much like carboxyl moieties, amino groups are favoured due to the hydrophilic properties they impart onto UCNPs and their ability to also be cross-linked via the well-established carbodiimide coupling protocol. Conversely, they exhibit positive charges at physiological $\mathrm{pH}$ which may be desirable for certain applications. The summary of the surface modified UCNPs via ligand engineering process with amino moieties is exhibited in Table 2.

Table 2. Summary of the surface modified UCNPs via ligand engineering with amino moieties.

\begin{tabular}{|c|c|c|c|c|c|c|}
\hline UCNP & Ligand & $\begin{array}{l}\text { Coordinating } \\
\text { Moiety }\end{array}$ & $\begin{array}{l}\text { Functional } \\
\text { Moiety }\end{array}$ & $\begin{array}{c}\text { Method of } \\
\text { Functionalisation }\end{array}$ & Application & Ref. \\
\hline $\mathrm{NaYF}_{4}: \mathrm{Yb}^{3+}, \mathrm{Tm}^{3+}$ & PEA & Phosphate & Amino & $\begin{array}{l}\text { EDC/NHS } \\
\text { Chemistry }\end{array}$ & $\begin{array}{l}\text { Remotely } \\
\text { triggered } \\
\text { anti-cancer } \\
\text { system }\end{array}$ & [25] \\
\hline $\mathrm{NaYF}_{4}: \mathrm{Yb}^{3+}, \mathrm{Tm}^{3+}$ & PEA & Phosphate & Amino & $\begin{array}{l}\text { Reductive } \\
\text { Amination }\end{array}$ & $\begin{array}{l}\text { Solid-phase } \\
\text { biosensing }\end{array}$ & [58] \\
\hline $\mathrm{NaGdF}_{4}: \mathrm{Yb}^{3+}, \mathrm{Er}^{3+}$ & PMAM & Amino & Amino & $\begin{array}{c}\text { Nucleophilic } \\
\text { Thiourea } \\
\text { Formation }\end{array}$ & $\begin{array}{l}\text { Targeted lectin } \\
\text { recognition }\end{array}$ & [59] \\
\hline
\end{tabular}

An exchange between oleate and o-phosphorylethanolamine (PEA), which exhibits both terminal amino and phosphate groups, was carried out on $\mathrm{NaYF}_{4}: \mathrm{Yb}^{3+}, \mathrm{Tm}^{3+} \mathrm{UCNPs}$ in research conducted by Fedoryshin et al. (2014) [25]. The exchange led to the affixing of primary amines to the surface of the particles for their use in a remotely triggered anti-cancer drug delivery system (as displayed in Figure 5). As phosphate exhibits both greater coordination sites and binding affinity than carboxylates, the exchange favours the replacement of oleate carboxylate groups with terminal phosphates [10]. Conjugation of the photocleavable prodrug ONB-5-FU to the UCNPs via carbodiimide chemistry involved the addition of NHS, resulting in the formation of an amide bond. Due to ONB-5-FU exhibiting an overlapping UV absorption range with that of UV emission range of the UCNPs, 
excitation of UCNPs resulted in $364 \mathrm{~nm}$ UV light emission that efficiently photocleaved the prodrug. This allowed for detachment and consequent release of 5-fluorouracil, where cleavage is proposed to occur at the C-N bond that couples ONB and 5-FU. It was determined that the rate of release could be tuned with laser power output $(10,30$ and $80 \mathrm{~mW})$ and that as high as $77 \%$ of the prodrug was effectively released via remote triggering through NIR excitation in comparison to traditional direct UV excitation. Laser excitation at $80 \mathrm{~mW}$ resulted in an observed initial rate constant $\left(\mathrm{k}_{\mathrm{o}}\right)$ of $130 \mu \mathrm{M}$ $\min ^{-1}$ while, conversely, at $10 \mathrm{~mW}$, a $\mathrm{k}_{\mathrm{o}}$ of $18 \mu \mathrm{M}$ min $^{-1}$ was observed.

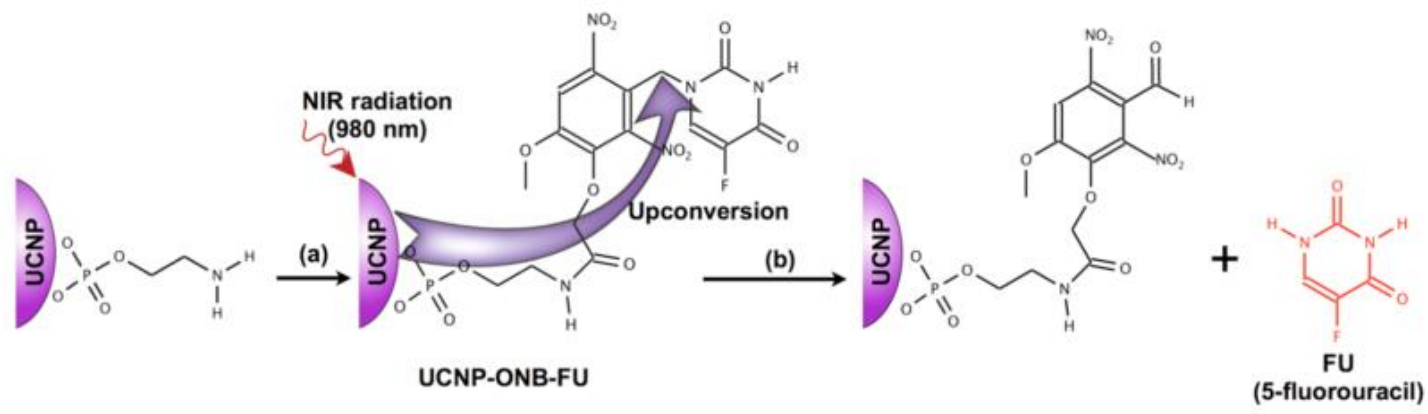

Figure 5. (a). Modification of water-soluble PEA-capped UCNPs coupled with ONB-FU. (b) NIR excitation $(980 \mathrm{~nm})$ of the UCNPs resulted in upconverted photo luminescent emission at $364 \mathrm{~nm}$ used for photocleaveage of ONB-FU and subsequent release of 5-fluorouracil. Reprinted with permission from [25]. Copyright 2014 American Chemical Society.

Similarly, work presented by Doughan et al. (2014) [58] utilises PEA to realise a biosensing application through solid-phase covalent immobilisation of UCNPs (Figure 6). A significant problem presented to the applications of UCNPs in aqueous mediums is the agglomeration of particles in solution, which can be overcome through the use of UCNPs in solid-phase at interfaces. Standard as-synthesised $\mathrm{NaYF}_{4}: \mathrm{Yb}^{3+}, \mathrm{Tm}^{3+} \mathrm{UCNPs}$ were transitioned to a hydrophilic phase via a ligand exchange with oleate ligands present on the UCNPs and PEA. The phosphate moiety of the PEA coordinates to the surface of the UCNPs whilst the terminal amines extend outward, providing hydrophilicity and conjugation capabilities.

Glass slides, which were used as the interface medium, were functionalised with surface silanol groups by washing with $\mathrm{NH}_{4} \mathrm{OH}$ and $\mathrm{HCl}$ in the presence of $\mathrm{H}_{2} \mathrm{O}_{2}$. Subsequently they were amine functionalised via (3-aminopropyl)trimethoxysilane (APTMS) followed by reductive amination with sodium cyanoborohyride $\left(\mathrm{NaBH}_{3} \mathrm{CN}\right)$. The resulting aldehyde-functionalised glass slides provided an interface for which the PEA-modified UCNPs could now be coupled and immobilised to through covalent bonding. Incubation of the glass slides over $2 \mathrm{~h}$ followed drop spotting of UCNPs with $\mathrm{NaBH}_{3} \mathrm{CN}$ on desired locations so as to allow reductive amination to occur and the formation of a subsequent alkyl amine bond between the underside of the UCNPs and slide (as shown in Figure 6).

The surface residing amino groups on the UCNPs were functionalised with thrombin after residual aldehyde groups on the slide were inactivated with ethanolamine in the presence of $\mathrm{NaBH}_{3} \mathrm{CN}$. Amine-modified thrombin specific aptamer- 1 was drop cast onto active UCNP spots after the surface amines were reacted with glutaraldehyde. As quantum dots (QDs) exhibit a spectral overlap with UCNPs, displaying an absorbance over their emission range $(\sim 330-490 \mathrm{~nm})$, they can be used as effective energy acceptors in an LRET-based energy donor-acceptor system of UCNPs and QDs. As a result, QDs were functionalised with thrombin specific aptamer-2 and subsequently incubated for $6 \mathrm{~h}$ with UCNPs so as to allow the aptamers to attach. If the aptamers have successfully attached, the UCNPs will undergo a LRET process with the QDs when excited at $980 \mathrm{~nm}$. Confirmation and quantification can be achieved via the consequent QD emission at $614 \mathrm{~nm}$ and peak ratio, whereby it was determined that the assay showed strong selectivity for thrombin through control testing. In contrast to $0.1 \mu \mathrm{M}$ thrombin, a $1 \mu \mathrm{M}$ solution of BSA displayed a signal that was $80 \%$ lower while 
also demonstrating a signal that was $90 \%$ lower for the non-specific adsorption of QDs onto the surface of the interface.

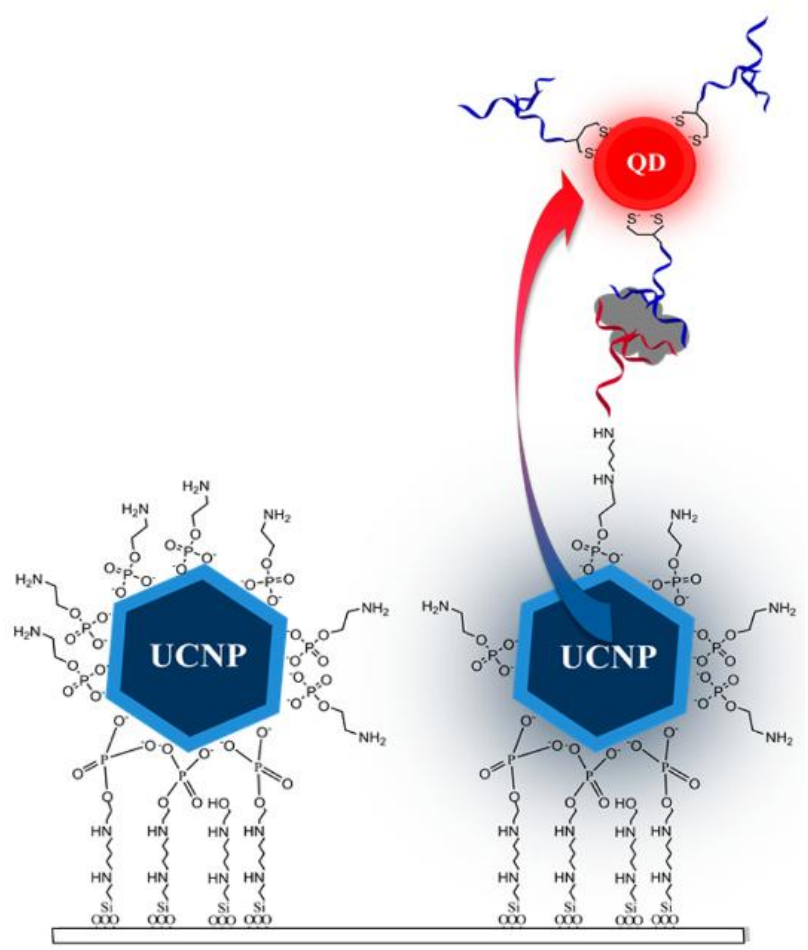

Figure 6. Schematic showing immobilization of PEA-UCNP on aldehyde functionalised coverslip and use in the detection of thrombin (grey) using thrombin-specific aptamer-1 (red) and aptamer-2 (blue). Reprinted with permission from [58]. Copyright 2014 American Chemical Society.

An endeavour to produce carbohydrate-coated UCNPs for lectin recognition was undertaken by Bogdan et al. (2010) [59]. After $\mathrm{NaGdF}_{4}: \mathrm{Yb}^{3+}, \mathrm{Er}^{3+}$ UCNPS were synthesised with oleate ligands present on the surface, they subsequently underwent a ligand-exchange with poly(amido)amine (PMAM). As PMAM exhibits four terminal amino moieties, one moiety can exchange and co-ordinate to the UCNP surface while the remaining three groups provide both hydrophilicity and further bioconjugation capabilities. Synthetic multivalent carbohydrates demonstrate efficient inhibition of protein-carbohydrate interactions due to strong binding affinities. Therefore, by cross-linking synthetic carbohydrates to the UCNPs, the UCNPs gain the ability to interact and detect bacteria or virus infections. The synthetic carbohydrate p-isothiocyanatophenyl a-D-mannopyranoside was coupled to the UCNPs via thiourea bond formation between the terminal amino groups residing on the UCNP surface and the terminal thiocyanate on the synthetic carbohydrate. Further testing through an LRET assay led to the determination that the mannose moiety successfully conjugated to protein receptors by use of a RITC-labelled plant lectin Con A (RITC-Con A). As the RITC-Con A absorption overlaps with the emission range of the UCNPs $(550 \mathrm{~nm})$, it gives off a characteristic emission at $585 \mathrm{~nm}$ that can indicate successful attachment of the carbohydrate to protein receptors after UCNP excitation. The group demonstrated that there was a matching boost in acceptor fluorescence to UCNP green emission decline after excitation of the UCNPs at $980 \mathrm{~nm}$. Furthermore, the addition of $\mathrm{Gd}^{3+}$ to the nanocore allows for great contrast when imaging via magnetic resonance imaging (MRI) as it exhibits a considerable magnetic moment.

\subsubsection{Thiol Moiety Modified UCNPs via Ligand Engineering}

Equivalently to carboxyl and amino moieties, thiol moieties can be used to co-ordinate to UCNPs, impart hydrophilicity and grant the capability to further conjugate biomolecules for 
extended application. Although they cannot undergo carbodiimide reactions, thiols can present an alternative option for operations where carboxyl and amino cannot be applied effectively. Table 3 summarised the surface modified UCNPs via ligand engineering with thiol moieties and their corresponding applications.

Table 3. Summary of the surface modified UCNPs via ligand engineering with thiol moieties.

\begin{tabular}{|c|c|c|c|c|c|c|}
\hline UCNP & Ligand & $\begin{array}{c}\text { Coordinating } \\
\text { Moiety }\end{array}$ & $\begin{array}{c}\text { Functional } \\
\text { Moiety }\end{array}$ & $\begin{array}{c}\text { Method of } \\
\text { Functionalisation }\end{array}$ & Application & Ref \\
\hline $\begin{array}{l}\mathrm{Fe}_{3} \mathrm{O}_{4} / \mathrm{NaYF}_{4}: \\
\mathrm{Yb}^{3+}, \mathrm{Er}^{3+}\end{array}$ & MUA & Carboxylate & Thiol & $\begin{array}{l}\text { Affinity to } \\
\mathrm{Fe}_{3} \mathrm{O}_{4}\end{array}$ & $\begin{array}{c}\mathrm{Fe}_{3} \mathrm{O}_{4} \text { enhanced } \\
\text { superparamagnetic } \\
\text { UCNPs }\end{array}$ & [49] \\
\hline $\begin{array}{c}\mathrm{NaYF}_{4}: \\
\mathrm{Yb}^{3+}, \mathrm{Er}^{3+}\end{array}$ & TGA & Thiol & $\begin{array}{l}\text { Carboxylic } \\
\text { Acid }\end{array}$ & $\begin{array}{l}\text { Electrostatic } \\
\text { Interactions }\end{array}$ & $\begin{array}{c}\mathrm{Ag}^{+} \text {-assisted } \\
\text { photothermal therapy } \\
\text { Dual-mode }\end{array}$ & [60] \\
\hline $\begin{array}{l}\mathrm{Yb}^{3+}, \mathrm{Tm}^{3+}: \\
\mathrm{BaF}_{2} / \operatorname{Ln}^{3+}: \mathrm{SrF}_{2}\end{array}$ & TGA & Thiol & $\begin{array}{l}\text { Carboxylic } \\
\text { Acid }\end{array}$ & $\begin{array}{l}\text { Ligand } \\
\text { Exchange }\end{array}$ & $\begin{array}{c}\text { luminescence } \\
\text { Active-core/Active-shell } \\
\text { synthesis of UCNPs }\end{array}$ & [61] \\
\hline $\begin{array}{c}\mathrm{NaYF}_{4}: \\
\mathrm{Gd}^{3+}, \mathrm{Eu}^{3+}\end{array}$ & MPA & Thiol & $\begin{array}{l}\text { Carboxylic } \\
\text { Acid }\end{array}$ & & $\begin{array}{l}\text { Combined optical and } \\
\text { MR imaging }\end{array}$ & [62] \\
\hline
\end{tabular}

Successful development of superparamagnetic $\mathrm{Fe}_{3} \mathrm{O}_{4} / \mathrm{NaYF}_{4}: \mathrm{Yb}^{3+}, \mathrm{Er}^{3+}$ hybrid nanoparticles was demonstrated by Shen et al. (2010) [49] whereby 11-mercaptoundecanoic acid (MUA) was surface modified onto $\mathrm{NaYF}_{4}$ : $\mathrm{Yb}^{3+}, \mathrm{Er}^{3+} \mathrm{UCNPs}$ via a ligand exchange with oleate ligands present on the as-synthesised particles. As MUA exhibits both terminal thiol and carboxylic moieties, it displays the ability to co-ordinate to the UCNPs via the carboxyl moiety whilst being capable of further cross-linking through residual thiol moieties. These thiol moieties play a crucial role in the cross-linking process due to the specific affinity they boast toward $\mathrm{Fe}_{3} \mathrm{O}_{4}$ NPs. Compared to UCNPs coated with 1,10-decanedicarboxylic acid (DDA) which exhibits terminal carboxyl moieties, the UCNPs@MUA were not only smaller in size than the UCNPs@DDA but also absorbed $\mathrm{Fe}_{3} \mathrm{O}_{4}$ NPs more densely. It is inferred that the MUA perhaps inhibits the growth of $\mathrm{Fe}_{3} \mathrm{O}_{4}$ on the surface of the UCNPs due to a robust interaction between Fe and S. Furthermore, the group present evidence to support effective magnetic separation ability whereby they explain that the ligand spacing between $\mathrm{Fe}_{3} \mathrm{O}_{4}$ and the UCNPs allows for the superparamagnetic properties of $\mathrm{Fe}_{3} \mathrm{O}_{4}$ to be kept intact.

Inversely, research by Dong, B. et al. (2011) [60] establishes the use of the thiol moiety as a co-ordinating moiety to the surface of $\mathrm{NaYF}_{4}: \mathrm{Yb}^{3+}, \mathrm{Er}^{3+} \mathrm{UCNPs}$ for therapeutic photothermal applications (as displayed in Figure 7). Notably, it has been reported that ligands which have been exchanged to UCNP surfaces via thiol coordination require additional functionalisation so as to undergo cell internalisation effectively [5]. As-synthesised UCNPs underwent a ligand exchange with thioglycolic acid (TGA). Absence of the characteristic -SH peak at $2600 \mathrm{~cm}^{-1}$ as determined via FTIR analysis led the group to assert that the -SH group is not only responsible for the connection to the UCNPs but the impartation of hydrophilic properties as well. The deprotonation and subsequent negative charge exhibited by the now surface residing carboxyl moieties was used to conjugate $\mathrm{Ag}^{+}$ions to the surface of the UCNP, forming an $\mathrm{Ag}^{+}$ionic shell. Addition of the $\mathrm{Ag}^{+}$shell to the nanoparticles granted an increase in temperature when the UCNPs were excited at $980 \mathrm{~nm}$, compared to UCNPs without the $\mathrm{Ag}^{+}$shell present on the surface. $\mathrm{Ag}^{+}$-coated UCNPs in solution reached an increased temperature of $303 \mathrm{~K}$ compared to $293 \mathrm{~K}$ from uncoated and irradiated UCNPs at the same power density range. Further tests led to the determination of significantly reduced cell viability of both HepG2 and BCap-37 cells, whereby after 20 min of irradiation viability reached as low as $4.62 \%$ and $5.43 \%$, respectively. 


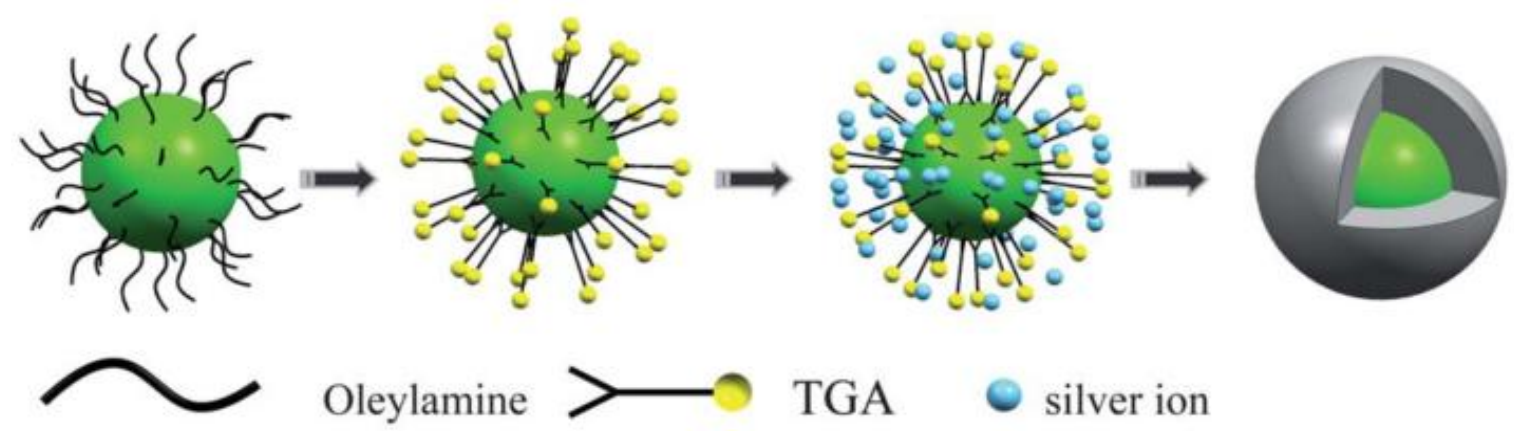

Figure 7. Schematic representation of the preparation of $\mathrm{NaYF}_{4}: \mathrm{Yb}^{3+}, \mathrm{Er}^{3+} @ \mathrm{Ag}-\mathrm{NPs}$. Reprinted with permission from [60]. Copyright 2011 The Royal Society of Chemistry.

Similarly, a novel method for the synthesis of sub-10 nm $\mathrm{Ln}^{3+-}: \mathrm{BaF}_{2} / \mathrm{Ln}^{3+}: \mathrm{SrF}_{2} \mathrm{UCNPs}$ was developed by Chen et al. (2011) [61], where $\mathrm{Ln}^{3+}=\mathrm{La}-\mathrm{Lu}$. Synthesis of $\mathrm{Tm}^{3+}, \mathrm{Yb}^{3+}: \mathrm{BaF}_{2} / \mathrm{Ln}^{3+}: \mathrm{SrF}_{2}$ active-core/active-shell UCNPS was followed by exchange of the terminal oleate ligands with TGA for the sole purpose of aqueous dispersal. Again, the thiol moiety co-ordinates to the surface of the UCNPs whilst the terminal carboxyl moieties reside on the surface of the UCNPs can grant further bioconjugation abilities. Design of an active-core/active-shell provides NIR-NIR dual-mode luminescence due to the upconverting emission of $\mathrm{Tm}^{3+}$ at $802 \mathrm{~nm}$ upon excitation of $\mathrm{Yb}^{3+}$, as well as the NIR downconverting emissions both of $\mathrm{Yb}^{3+}$ at $975 \mathrm{~nm}$ and $\mathrm{Nd}^{3+}$ at $1054 \mathrm{~nm}$. Furthermore, shell encapsulation of the core allows for protection of core ions from external interaction such as solvents and ligands that may cause vibrational deactivation.

Lastly, related work published by Kumar et al. (2009) [62] also establishes the use of the thiol moiety as a co-ordinating moiety to the UCNP surface for a combined optical and magnetic resonance imaging application. After the synthesis of $\mathrm{NaYF}_{4}: \mathrm{Gd}^{3+}, \mathrm{Eu}^{3+} \mathrm{UCNPs}$, as-present oleate ligands were exchanged with 3-mercaptopropionic acid (MPA), a ligand that has both a thiol and carboxyl moiety incorporated into its structure. The thiol moiety of MPA co-ordinates to the surface of the UCNPs whilst the residual carboxyl moieties provide further functionality by means of bioconjugation. Various tumour-specific antibodies were conjugated to the nanoparticles, such as anti-mesothelin, anti-claudin 4, transferrin via carbodiimide chemistry between terminal amino groups on the antibodies and the surface carboxyl groups of the UCNPs. Confocal images of Panc 1 cells confirmed substantial enhancement of cell uptake for antibody modified UCNPs compared to UCNPs without antibody modification, a result of a receptor-mediated process. Furthermore, it has been reported that corresponding receptors to the antibodies are overexpressed on the surface of these particular cells [63] and as a result, a high amount of UCNPs can be seen targeting and binding specifically to the receptors on the surface of the cells.

\subsection{Silanisation of UCNPS}

Silanisation, a popular method for UCNP surface modification due to well-established surface chemistry [3], allows for the controlled growth and simultaneous functionalisation of a silica shell on UCNPs. Dense $\left(\mathrm{dSiO}_{2}\right)[18,64,65]$ and mesoporous $\left(\mathrm{mSiO}_{2}\right)[11,15,25,37,39,66,67]$ silica shells are common surface modifications to UCNPs due to enhanced bio-compatibility and stability within hydrophilic mediums, such as biological fluids, and present minimal influence on luminescence [5]. Encapsulation of nanoparticles in a silica shell coating allows them to be protected from surrounding aqueous media, thus enhancing both the dissolution and denaturation stability of the nanoparticles and preventing their dissolution into individual ionic species $[4,6,7]$. This aids in avoiding the release of toxic ions comprising the nanoparticles and a substantially decreased likelihood of an anaphylactic response. Furthermore, the chemically inert nature of silica $\left(\mathrm{SiO}_{2}\right)$ ensures that no degradation of the shell will occur whilst terminal hydroxyl $(-\mathrm{OH})$ groups on the surface of the shell allow for subsequent 
functionalisation $\left(-\mathrm{COOH},-\mathrm{NH}_{2}\right.$ or $\left.-\mathrm{SH}\right)$ and/or conjugation of biomolecules that can be used for bio-sensing as well as drug and gene delivery applications [4-6,35,36,40,65].

The option to simultaneously functionalise the silica shell during synthesis or postsynthesis can be done easily with silanes that typically undergo a further condensation reaction at the terminal hydroxyls present on the silica shell surface. Examples of such silanes include (3-aminopropyl)trimethoxysilane $[4,5,36,37,65]$ (APTES) which imparts amine $\left(-\mathrm{NH}_{2}\right)$ functionalisation, carboxyethylsilanetriol $[4,5,17,68]$ (CEST) that provides carboxylic $(-\mathrm{COOH})$ functionalisation and (3-mercaptopropyl)trimethoxysilane [37,69] (MPTMS) which grants thiol $(-\mathrm{SH})$ functionalisation. Amine-terminated functional groups are the most common silica surface functionalisation, followed behind by carboxyl functionalisation $[3-5,29,36]$. This is due to the hydrophilic nature of these moieties and, as previously stated, the established coupling process between these functional groups and many biomolecules via carbodiimide chemistry that links amines and carboxylics to form an amide bond [3-5,7,34]. One of the most notable advantages of silanisation is ability to tune the thickness of the silica shell, a variable that is dependent on the concentration of the selected silyl ether. This is particularly useful in both the realisation of drug delivery systems and bioassays where the thickness of the shell can be optimised for drug loading as well as luminescent resonance energy transfer (LRET) mechanisms where by luminescent energy emitted by the UCNPs is commonly transferred to a bio-conjugated compound or biomolecule $[3,19,24,25,29,30]$.

\subsubsection{Carboxyl Moiety Modified UCNPs via Silanisation}

Functionalisation of silica with carboxyl moieties is a common approach for the preparation of UCNPs for various biomedical operations. The negatively-charged electrostatic interactions they exhibit may be attractive in use. Furthermore, their use in forming amide bonds with biomolecules through well-established carbodiimide chemistry makes them desirable candidates. A summary of the surface modified UCNPs via silanisation with carboxyl moieties can be seen in Table 4.

Table 4. Summary of the surface modified UCNPs via silanisation with carboxyl moieties.

\begin{tabular}{|c|c|c|c|c|c|}
\hline UCNP & $\begin{array}{l}\text { Silica } \\
\text { Type }\end{array}$ & $\begin{array}{l}\text { Functional } \\
\text { Moiety }\end{array}$ & Method & Application & Ref. \\
\hline $\mathrm{NaYF}_{4}: \mathrm{Yb}^{3+}, \mathrm{Er}^{3+}$ & $\mathrm{dSiO}_{2}$ & $\begin{array}{l}\text { Carboxylic } \\
\text { Acid }\end{array}$ & \multirow{2}{*}{$\begin{array}{l}\text { Electrostatic } \\
\text { Interactions }\end{array}$} & $\begin{array}{l}\text { RCA-120 functionalised UCNPs } \\
\text { for biolabeling }\end{array}$ & [17] \\
\hline $\begin{array}{l}\mathrm{NaYF}_{4}: \mathrm{Yb}^{3+}, \mathrm{Er}^{3+} \text { and } \\
\mathrm{NaGdF}_{4}: \mathrm{Yb}^{3+}, \mathrm{Er}^{3+}\end{array}$ & $\mathrm{dSiO}_{2}$ & $\begin{array}{l}\text { Carboxylic } \\
\text { Acid/Amino }\end{array}$ & & $\begin{array}{l}\text { Electraphoretic separation and } \\
\text { purification of UCNPs@ } \mathrm{dSiO}_{2}\end{array}$ & {$[70]$} \\
\hline $\mathrm{NaYF}_{4}: \mathrm{Yb}^{3+}, \mathrm{Er}^{3+}$ & $\mathrm{dSiO}_{2}$ & $\begin{array}{l}\text { Carboxylic } \\
\text { Acid }\end{array}$ & \multirow{2}{*}{$\begin{array}{l}\text { EDC/NHS } \\
\text { Chemistry }\end{array}$} & $\begin{array}{l}\text { Highly sensitive DNA-based } \\
\text { biosensor }\end{array}$ & [20] \\
\hline $\mathrm{NaYF}_{4}: \mathrm{Yb}^{3+}, \mathrm{Er}^{3+}$ & $\mathrm{dSiO}_{2}$ & $\begin{array}{l}\text { Carboxylic } \\
\text { Acid }\end{array}$ & & Oligonucleotide-based biosensor & [22] \\
\hline
\end{tabular}

A versatile system for biolabeling applications was developed by Liu et al. (2012) [17] following the dense silanisation of $\mathrm{NaYF}_{4}: \mathrm{Yb}^{3+}, \mathrm{Er}^{3+}$ UCNPs. As-synthesised UCNPs with residing oleate capping agents underwent a reverse microemulsion reaction with TEOS to provide shell thicknesses between $1.5 \mathrm{~nm}$ and $6 \mathrm{~nm}$. Silica shells not only provide hydrophilicity to the UCNP but also allow for protection of the UCNP nanocore via encapsulation, as well as granting further functionalisation capabilities by interaction with residual surface silanol groups. Following the coating of silica, addition of CEST to the UCNP solution led to terminal triol groups undergoing condensation with the surface silanols, a result of ammonia-assisted hydrolysation. Ultimately, a robust ether bond is formed between the UCNPs and CEST, therefore, affixing terminal carboxyl groups to the surface of the UNCPs. Furthermore, the effects of $\mathrm{pH}$ on the carboxyl moieties were investigated (displayed in Figure 8), demonstrating that while the particles displayed excellent colloidal stability at alkaline $\mathrm{pH}$, an increase in particle aggregation (correlating with particle size) is seen at neutral $\mathrm{pH}$. Although this data demonstrates the ability to store the nanoparticles long-term in alkaline solutions, it also 
highlights the greatest obstacle in the field, which is the difficulty in obtaining monodispersed and un-agglomerated nanoparticles for use at a biological $\mathrm{pH}$. This behaviour can be explained by the protonation of the terminal carboxylate groups (and an increase in the concentration of protons) at lower $\mathrm{pH}$ levels. The addition of a proton to the carboxylate neutralises the formal negative charge held by the hydroxyl group and, thus, reduces the previous amount of repulsion between the negatively charged carboxlate and silica shell, leading to an increase in agglomeration (and hence greater particle size). To demonstrate the biolabeling and LRET application of the UCNPs, the group conjugated Ricinis Communis Agglutinin (RCA 120) to the UCNPs so as to provide interaction with HeLa cells. Upconversion luminescence microscopic imaging illustrated that no upconversion was observed when UCNPs@ $\mathrm{dSiO}_{2}-\mathrm{COOH}$ were incubated with HeLa cells whilst UCNPs coupled with RCA-120 demonstrated significant upconversion, suggesting the RCA-120 successfully targeted and interacted with the HeLa cells.

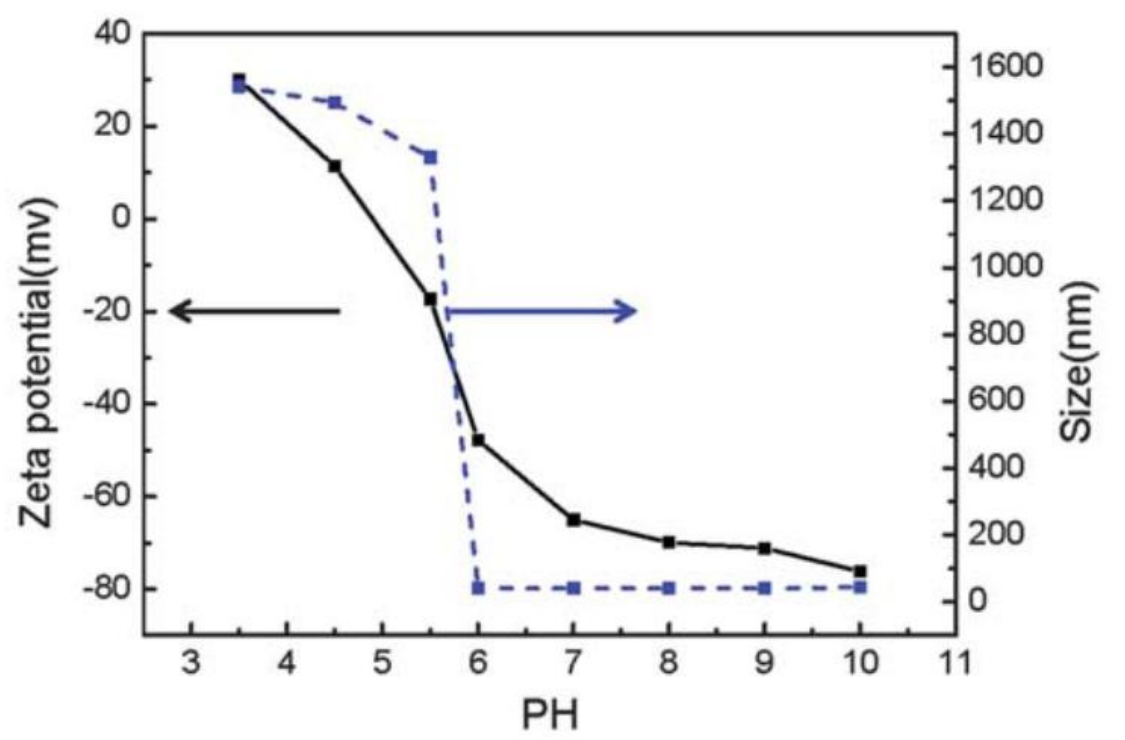

Figure 8. Zeta-potential and DLS size distribution as a function of the solution $\mathrm{pH}$ value. Reprinted with permission from [17]. Copyright 2013 Royal Society of Chemistry.

The use of agarose gel electrophoresis for the detection, separation and purification of various UCNPs based on their surface charge was reviewed by Hlaváček et al. (2014) [70]. Various UCNPs $\left(\mathrm{NaGdF}_{4}\right.$ and $\left.\mathrm{NaYF}_{4}: \mathrm{Yb}^{3+}, \mathrm{Er}^{3+}\right)$ were coated with $\mathrm{dSiO}_{2}$ and subsequently functionalised with either APTES or CEST (as displayed in Figure 9). Following this, bare UCNPs@dSiO ${ }_{2}, \mathrm{UCNPs} @ \mathrm{dSiO}_{2}-\mathrm{COOH}$ and UCNPs@dSiO ${ }_{2}-\mathrm{NH}_{2}$ were separated onto vertical agarose gel whereby electrophoresis was carried out for $30 \mathrm{mins}$ at $100 \mathrm{~V}$. Separation of particles can be done size-dependently due to both the terminal silanol groups $\left(\mathrm{pK}_{\mathrm{a}}=7.0\right)$ and carboxyl groups $\left(\mathrm{pK}_{\mathrm{a}}=4.5\right)$ providing a pervasive negative charge across the surface of the UCNPs. UCNPs exhibiting bare silica shells demonstrated a longer diffuse zone than carboxylated UCNPs, with bare silica particle being observed to form several distinct bands. Furthermore, a fraction of the bare particles did not entire the agarose gel with the formation of several bands indicates varying clumps of agglomerated nanoparticles. Conversely, UCNPs functionalised with terminal carboxyl groups exhibited only a single band when separated under electrophoresis, indicating monodispersed and unagglomerated particles. Moreover, it was determined that fluorescently doping the UCNPs for greater characterisation did not affect the overall surface charge, size or agglomeration of particles. Following electrophoretic separation, the terminal carboxyl groups were inked to terminal amino groups present on the bovine serum albumin (BSA) via carbodiimide chemistry. To further test the separation abilities of the particles via electrophoresis, the newly bioconjugated particles were added to agarose gel under electrophoresis. Although the presence of the UCNPs was well-defined in a single band, the electrophoretic mobility of the particles 
was substantially reduced following bioconjugation. Separation via electrophoresis not only led to single band separation of conjugated UCNPs but of excess BSA as well, thus successfully allowing the separation of conjugated UCNPs from left over BSA reagent.

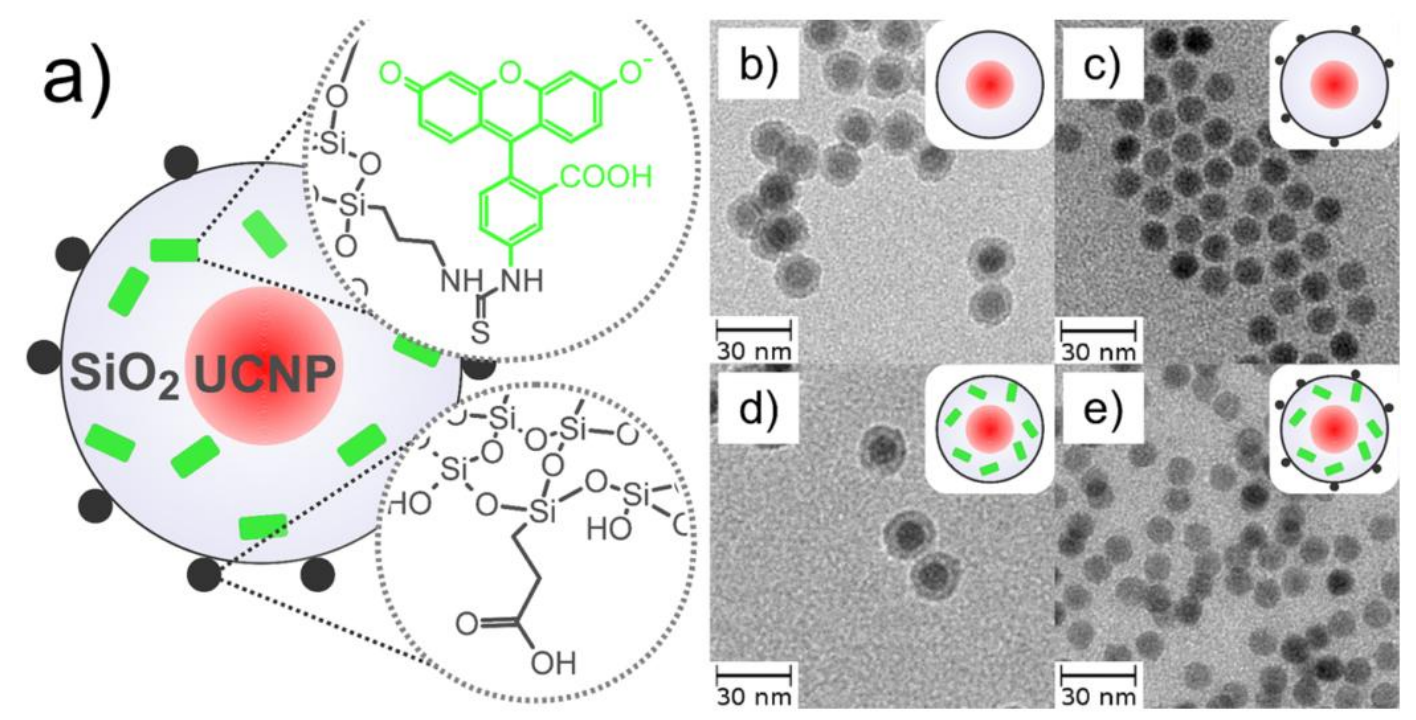

Figure 9. (a) Schematic drawing of silica-coated UCNPs. UCNPs were coated with either a (b) bare or (c) carboxylated (black dots) silica shell. In parallel approaches, fluorescein (green) was added to the (d) bare or (e) carboxylated silica shell. Reprinted with permission from [70]. Copyright 2014 American Chemical Society.

Alonso-Cristobal et al. (2015) [20] developed carboxyl-functionalised $\mathrm{UCNPs} @ \mathrm{dSiO}_{2}$ as a platform for a highly sensitive DNA-based sensor (displayed in Figure 10). Following the synthesis of $\mathrm{NaYF}_{4}$ : $\mathrm{Yb}^{3+}, \mathrm{Er}^{3+} \mathrm{UCNPs}$, the particles were subsequently coated with a $\mathrm{dSiO}_{2}$ shell via reverse microemulsion. Additionally, the surface silanols groups were condensated with APTES to provide terminal amine functionality and hydrophilicity. However, the terminal amine groups were subsequently subjected to a reaction with succinic anhydride, leading to a ring open reaction that results in formation of an amide bond and affixation of terminal carboxyl groups to the silica shell as shown in Figure 10). Not only does the conversion to carboxyl moieties provide greater hydrophilicity to the UCNPs but it provides the capability to bioconjugate ss-DNA covalently through its terminal amino group. By using carbodiimide chemistry, the terminal carboxyl groups were used to consequently form an amido bond between the UCNP and ss-DNA. As ss-DNA can undergo hybridisation with complementary strands of DNA, complementary DNA attached to graphene oxide (GO) was added to a solution of UCNP@dSiO ${ }_{2} @$ ss-DNA. Hybridisation of the DNA leads to double stranded DNA (ds-DNA) that does not actively interact with the attached GO and therefore allows emission from the UCNPs to be observed once excited at $980 \mathrm{~nm}$. Conversely, non-complementary DNA attached to GO will not undergo hybridisation with ss-DNA present on the UCNP and therefore will interact with the GO. As the absorption spectrum of GO completely overlaps with that of the emission spectrum of the UCNPs, the emission of the UCNPs is quenched via an LRET process. The system described here permits the realisation of a highly selective and sensitive DNA-based biosensor that can qualitatively detect DNA through a turn "on"/ turn "off" mechanism. 


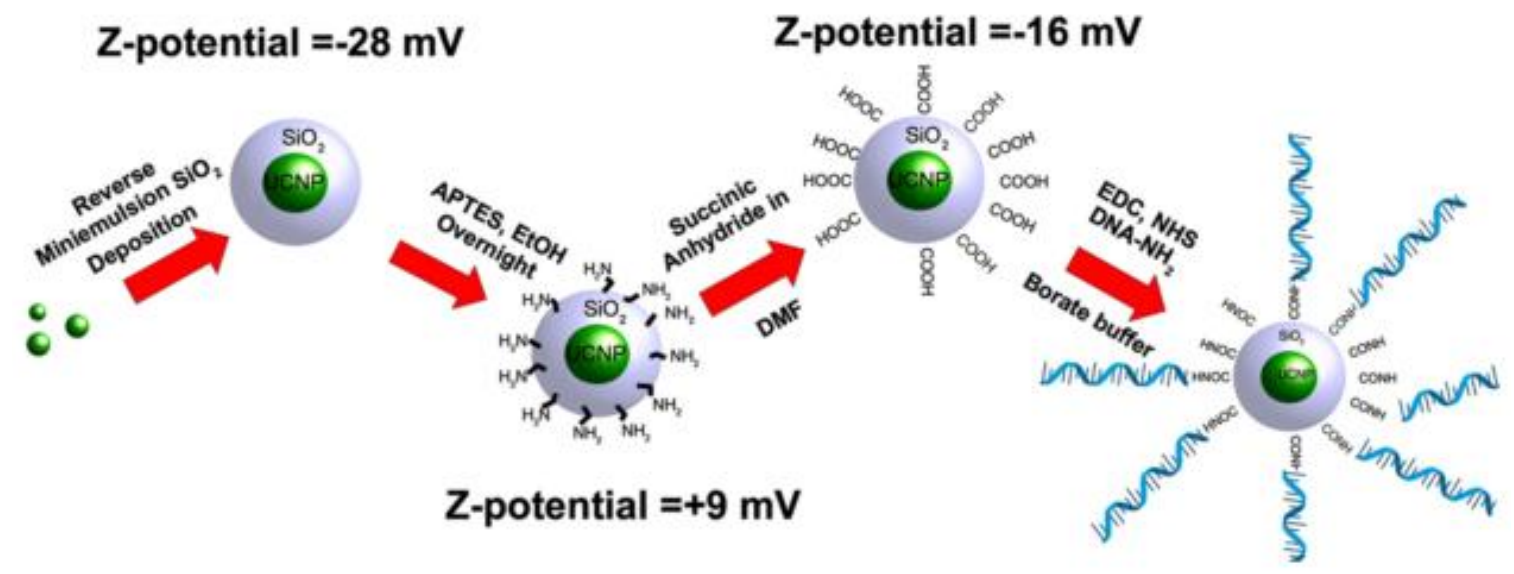

Figure 10. An experimental scheme for the modification of UCNPs by Alonso-Cristobal et al. for a LRET-based DNA sensor. Reprinted with permission from [20]. Copyright 2015 American Chemical Society.

In a similar manner, Mendez-Gonzalez et al. (2017) [22] functionalised $\mathrm{NaYF}_{4}: \mathrm{Yb}^{3+}, \mathrm{Er}^{3+} \mathrm{UCNPs}$ for their use in an oligonucleotide-based sensor (shown in Figure 11). The particles were coated with a $\mathrm{dSiO}_{2}$ shell where they were then subsequently functionalised with APTES to provide hydrophilicity to the UCNPs. Following this, the residual amino groups were reacted with succinic anhydride to afford terminal carboxyl terminals to the surface of the silica shell via a ring opening reaction as previously mentioned. As a result, the formation of a newly formed amide bond between the terminal amines on the UCNP and the anhydride give rise to carboxyl moieties on the surface of the UCNPs. Although the carboxyl moieties provide greater hydrophilicity than the amine groups, their main role is to provide cross-linking capabilities. They granted the opportunity to cross-link azide-modified ss-DNA to the surface carboxyl groups via carbodiimide chemistry interaction with terminal amino groups present on the DNA. As a consequence, the now terminal azide group present on the surface of the UCNPs affords the ability to undergo highly selective and sensitive click chemistry reactions. The double bonds present on the terminal azide groups can undergo 1,3-dipolar cycloaddition with the alkyne bonds present on the dibenzocyclooctyne (DBCO), which has been modified onto an end of biotin-modified complementary ss-DNA. After addition of the DBCO-ssDNA-biotin into a solution containing the carboxyl-modified UCNPs, the UCNPs were selectively trapped on a streptavidin-coated surface via click chemistry interaction. Consequently, upconversion emission intensity, which was proportional to the target concentration present in the sample, was emitted on UCNP excitation at $980 \mathrm{~nm}$. Not only can this system be used as a screening device to detect both RNA and DNA oligonucleotides but the group also determined a substantially low detection limit of around $1 \times 10^{-17}$ moles $(100 \mathrm{fM})$.

\subsubsection{Amino Moiety Modified UCNPs via Silanisation}

Surface functionalisation of silane modified UCNPs with amino moieties can be considered to be the most prevalent of the base functionalisations for silica modifications. As aforementioned, this is due to their ease of involvement with familiar carbodiimide chemistry, the additional hydrophilicity that they impart and the positive charge that they can exhibit. A summary of surface modified UCNPs via silanisation with amino moieties can be seen in Table 5 . 


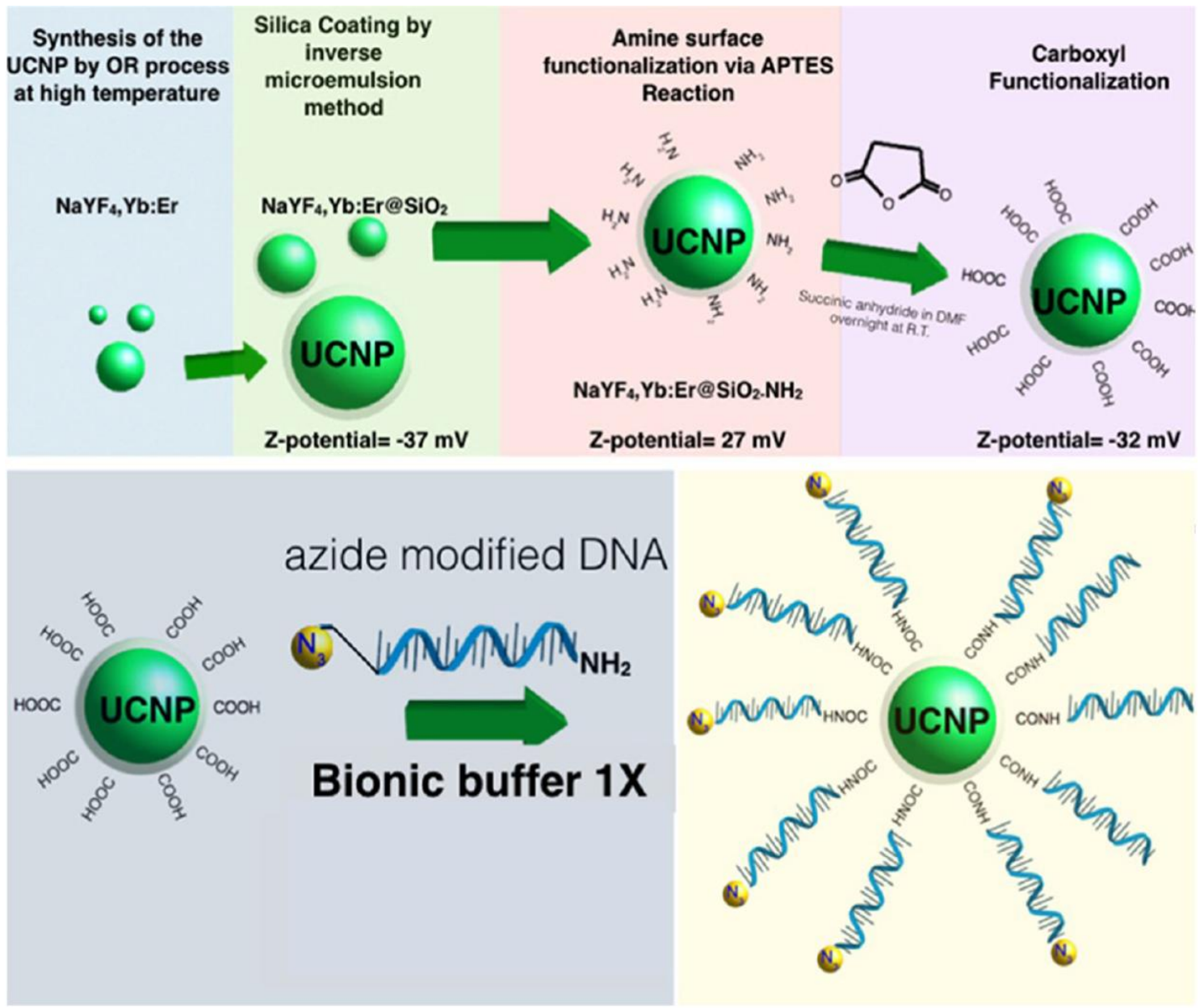

Figure 11. An experimental illustration for the synthesis and functionalisation of UCNPs by Mendez-Gonzalez et al. for a LRET-based oligonucleotide sensor. Reprinted with permission from [22]. Copyright 2017 American Chemical Society.

Table 5. Summary of the surface modified UCNPs via silanisation with amino moieties.

\begin{tabular}{cccccc}
\hline UCNP & $\begin{array}{c}\text { Silica } \\
\text { Type }\end{array}$ & Functional Moiety & Method & Application & Ref. \\
\hline $\mathrm{NaYF}_{4}: \mathrm{Yb}^{3+}, \mathrm{Er}^{3+}$ & $\mathrm{dSiO}_{2}$ & $\begin{array}{c}\text { Amino/Carboxylic } \\
\text { Acid }\end{array}$ & $\begin{array}{c}\text { Electrostatic } \\
\text { Interactions }\end{array}$ & $\begin{array}{c}\text { Investigation of the effect of } \\
\text { surface charge on cellular } \\
\text { internalisation } \\
\text { Photocaged and controlled } \\
\text { chemotherapy System }\end{array}$ & {$[71]$} \\
$\mathrm{NaYF}_{4}: \mathrm{Yb}^{3+}, \mathrm{Tm}^{3+}$ & $\mathrm{dSiO}_{2}$ & Amino & $\begin{array}{c}\text { EDC/NHS } \\
\text { Chemistry }\end{array}$ & $\begin{array}{c}\text { Azobenzene-gated remotely } \\
\text { triggered drug delivery system }\end{array}$ & {$[24]$} \\
$\mathrm{NaYF}_{4}: \mathrm{Yb}^{3+}, \mathrm{Tm}^{3+} @$ & $\mathrm{NSiO}_{2}$ & Amino & Targeted delivery of siRNA & {$[73]$} \\
$\mathrm{NaYF}_{4}: \mathrm{Yb}^{3+}, \mathrm{Er}^{3+}$ & $\mathrm{mSiO}_{2}$ & Amino & & & \\
\hline
\end{tabular}

A unique research angle taken by Zhang et al. (2014) [71] investigated the surface charge of $\mathrm{dSiO}_{2}$ coated $\mathrm{NaYF}_{4}: \mathrm{Yb}^{3+}, \mathrm{Er}^{3+} \mathrm{UCNPs}$ and their effect on both cellular interactions as well as cytotoxicity. The $\mathrm{dSiO}_{2}$ was functionalised with terminal surface carboxyls via the use of carboxyethylsilanetriol (CEST), which allowed for conjugation of $\mathrm{NH}_{2}-\mathrm{PEG}-\mathrm{NH}_{2}$ ligands by the use of carbodiimide chemistry involving sulfo-NHS. The formation of an amide bond resulted in $\mathrm{UCNP} @ \mathrm{dSiO}_{2} @ P E G-\mathrm{NH}_{2}$ particles that exhibit terminal amino groups, undergoing protonation at physiological $\mathrm{pH}$ and resulting in positively charged surface moieties. The cellular internalisation and uptake of the UCNPs was measured via luminescence and inductively-coupled plasma mass-spectrometry (ICP-MS). Upconversion luminescent intensity was found to be highest for UCNPs@dSiO ${ }_{2} @ P E G-\mathrm{NH}_{2}$ followed 
by UCNPs@dSiO $2-\mathrm{COOH}$ when imaged after incubation with HepG-2- and HeLa cells, with measurements conducted via ICP-MS confirming the uptake efficiency of the particles. Further testing through the use of a conventional MTT assay determined the amine terminated nanoparticles to have substantially greater cytotoxicity than the carboxyl terminated particles. Moreover, ICP-MS measurements determined UCNPs@ $\mathrm{dSiO}_{2} @ \mathrm{PEG}-\mathrm{NH}_{2}$ to release greater intracellular amounts of $\mathrm{Y}$ ions than UCNPs@ $\mathrm{dSiO}_{2}-\mathrm{COOH}$, as a response to intracellular ROS. Overall, it was determined that a net positive surface charge account for greater cell internalisation of particles and, thus, a greater cytotoxicity than those with a net negative surface charge, for HepG-2 and HeLa cells.

Chien et al. (2013) [72] showcases the development of a targeted and photocontrolled caged chemotherapy UCNP-based system (illustrated in Figure 12) where $\mathrm{NaYF}_{4}$ : $\mathrm{Yb}^{3+}, \mathrm{Tm}^{3+} \mathrm{UCNPs}$ are coated by TEOS to provide a $\mathrm{dSiO}_{2}$ shell. They were subsequently functionalised with APTES, thereby imparting terminal amino groups to the surface of the UCNPs and greater hydrophilicity. Successful functionalisation of the amino groups to the surface of the silica was confirmed through an additional coupling of $\mathrm{N}$-succinimidyl 3(2-pyridyldithio)-propionate (SPDP) to the amine groups, which can then be cleaved through reduction of its disulphide bond by dithiothreitol (DTT). The cleavage results in the release of pyridine-2-thione (P2T) and demonstrates absorbance at $343 \mathrm{~nm}$ that can be used to quantify the release of the P2T and subsequently the successful functionalisation as well as occupation of the amino groups. DOX molecules were thiolated followed by consequent conjugation to the surface residual SPDP molecules where release of DOX molecules can be monitored and quantified via consequent P2T release absorbance at $343 \mathrm{~nm}$ as well as fluorescent emission of free-DOX in the supernatant, at $555 \mathrm{~nm}$. It was determined that $\sim 2 / 3$ of the amino groups were occupied by SPDP, allowing for further conjugation of remaining residual surface groups with PEG molecules via carbodiimide chemistry involving NHS. As PEG exhibits terminal carboxyl groups, they were used to further cross-link folic acid (FA) via the terminal - $\mathrm{NH}_{2}$ FA groups by a subsequent carbodiimide reaction. The targeting capabilities of FA coupled with lysosomal enzymes and their ability to cleave the SPDP disulphide bond allows for the realisation of a targeted chemotherapy delivery method. Moreover, the group demonstrated further functionalisation between the terminal FA-COOH groups and 2-nitrobenzylamine (NBA), a photocaging molecule via another carbodiimide reaction. The photocaging functionality displayed by NBA can allow for the remote triggering of NBA removal and subsequent uptake by desired cells in a localised region. Although this design is impressive in approach, both inefficient endocytosis and folate receptor expression levels inhibit the overall release of doxorubicin when used in application.

Liu et al. (2013) [24] examined the controlled release of doxorubicin from $\mathrm{NaYF}_{4}$ : $\mathrm{Yb}^{3+}$, $\mathrm{Tm}^{3+} @ \mathrm{NaYF}_{4}$ core shell UCNPs that were functionalised with azobenzene-gated mesoporous silica (as demonstrated in Figure 13). After the coating of $\mathrm{mSiO}_{2}$, it is possible to separately functionalise the surface of the silica shell as well as the pores of the silica. Consequently, APTES was modified with 4-(phenyl)azobenzoyl chloride via the terminal APTES amino group followed by condensation of the resultant $\mathrm{N}$-(3-triethoxysilyl)propyl-4-phenylazobenzamide with terminal hydroxyl groups present inside the $\mathrm{mSiO}_{2}$ pores. The surface of the silica shell was functionalised with APTES, imparting terminal amino groups that were then used to cross-link TAT peptides via carbodiimide chemistry, for enhanced cellular uptake. Following the loading of DOX, it was determined that the positive zeta potential $(+2.2 \mathrm{mV})$ of doxorubicin allowed for strong attachment to the inside of mesopores due to the negative zeta potential $(-40.6 \mathrm{mV})$ exhibited by the silica, leading to strong charge interactions and hydrogen bond formations with residual terminal silanols on the silica surface. Advantageously, this charge-charge interaction allows for doxorubicin to be transported throughout aqueous mediums with minimal to no loss of the drug from the pores unless remotely triggered via conformations in the azobenzene molecule (Figure 13). These are a result of LRET mechanisms arising from both UV and visible light emissions of the UCNP after excitation at $980 \mathrm{~nm}$, where the absorption range of the azobenzene molecule $(330 \mathrm{~nm}-440 \mathrm{~nm}$ ) partially overlaps with the emission range of the UCNPs (350 nm-450 nm). Furthermore, it is demonstrated that visible light emission resulted in a 
trans conformation of the molecule whilst conversely UV light emission result in a cis conformation, thus resulting in a wagging motion that pushes out the loaded DOX molecules in a localised region.

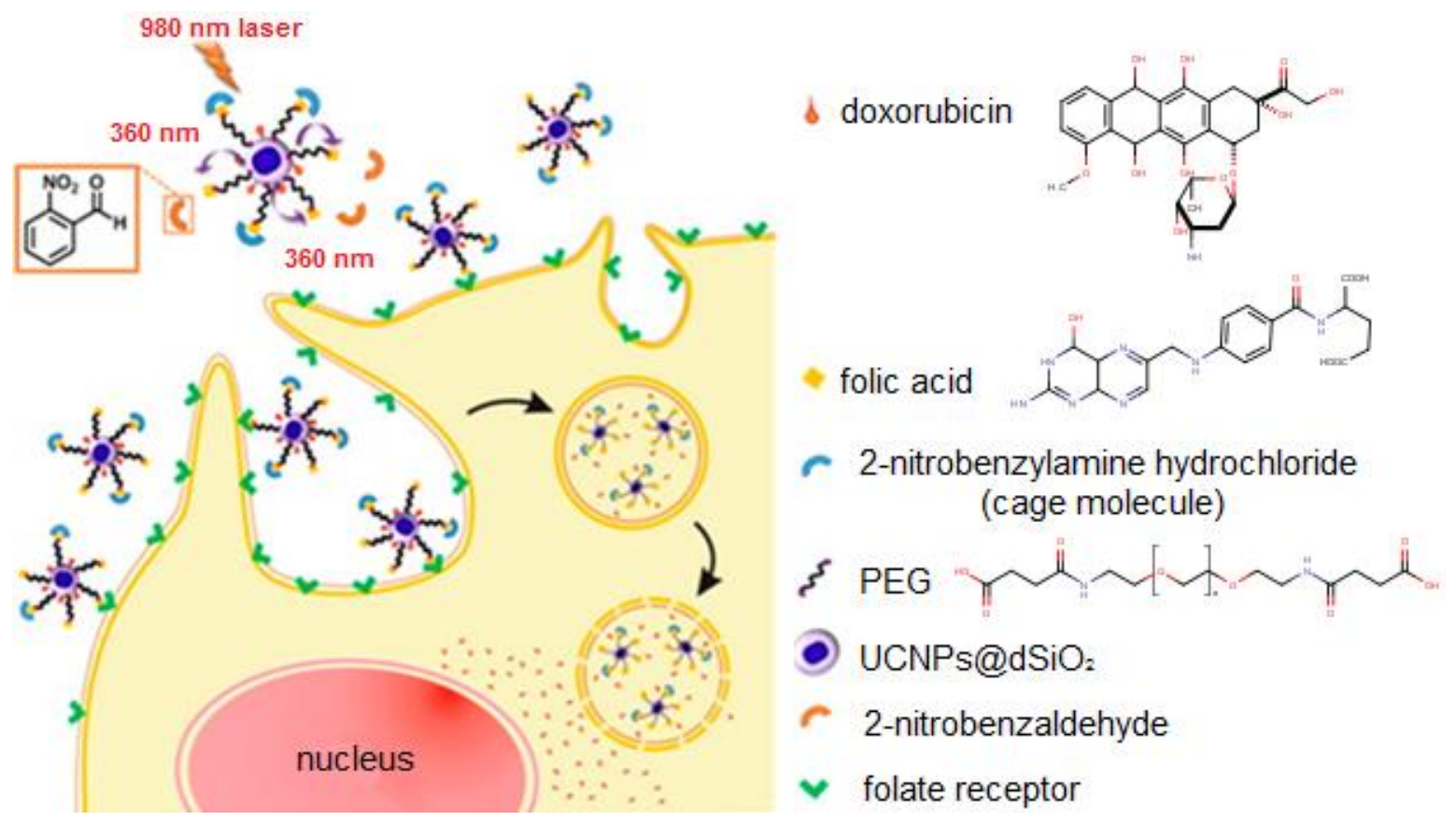

Figure 12. Illustration of photocaged UCNPs following NIR laser activation to remove cage molecules and subsequent targeting of cancer cells. Reprinted with permission from [72]. Copyright 2013 American Chemical Society.

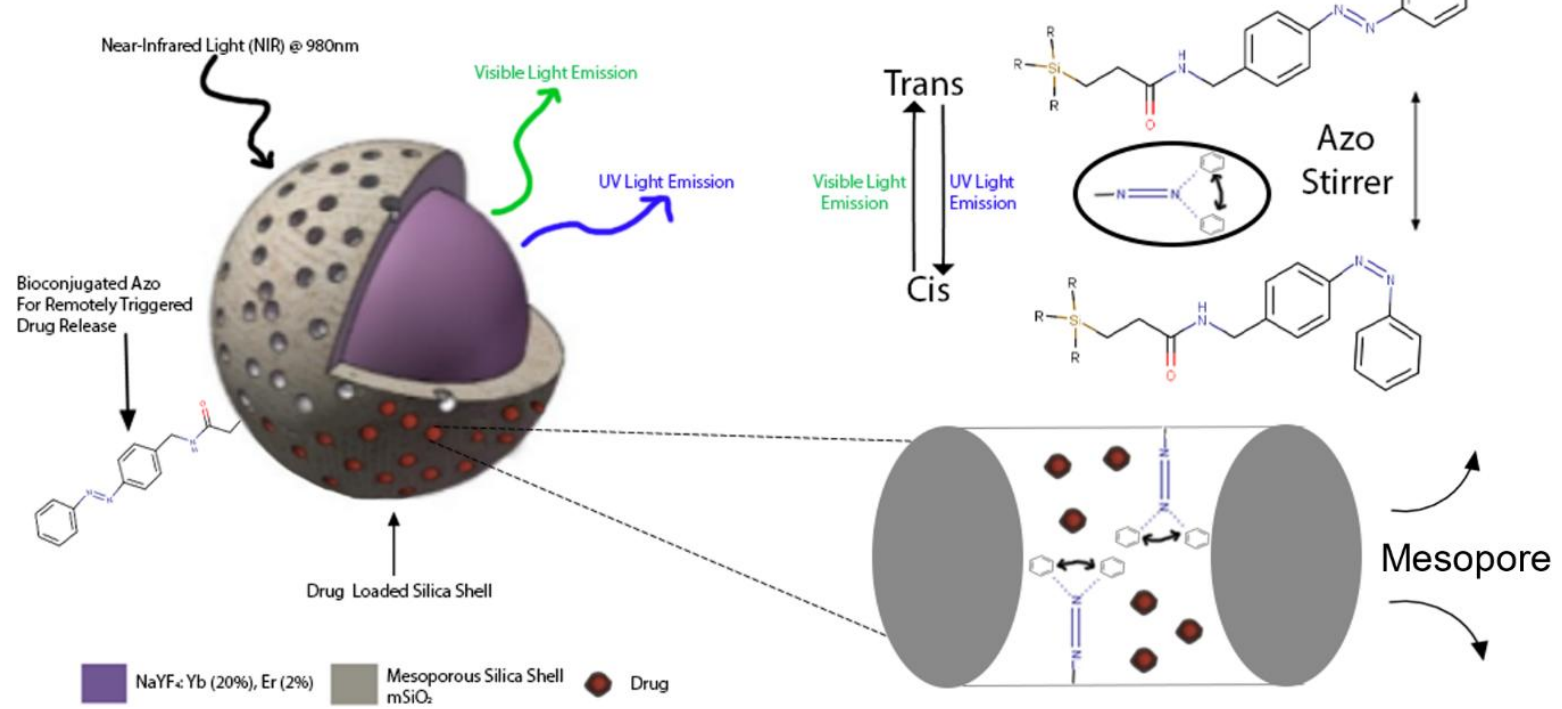

Figure 13. Mechanism of the azo-gated, remotely triggered drug delivery system developed by Liu et al. (2013) [24]. Adapted with permission from [24,27]. Copyright 2016 Optical Society of America and 2013 John Wiley and Sons, respectively.

Although the following research does not directly involve the mesoporous encapsulation of UCNPs, the same principles can easily be applied to $\mathrm{mSiO}_{2}$ coated UCNPs for drug delivery applications. Manzano et al. (2008) [74] investigated the effect of amine functionalised mesoporous silica on the controlled drug delivery of ibuprofen. They determined the amine functionalisation to 
have increased drug loading capacity by $\sim 10 \%$ (due to conjugation of drug to surface of particles as well as pores) as well as resulting in a controlled, slow release of ibuprofen in comparison to non-functionalised, irregular shaped mesopores. This is due to the interactions between the positively protonated $-\mathrm{NH}_{3}^{+}$groups within the pores and negatively-charged $-\mathrm{COOH}$ moiety present on the ibuprofen. Further research conducted by Basaldella and Legnoverde (2010) [75] determined the effects on sulphonic and amine functionalised mesoporous silica in the delivery of cephalexin, which exhibited a two-step prolife: (i) fast delivery $(<5 \mathrm{~h})$ and (ii) slow release $(>30 \mathrm{~h})$. Similarly, they demonstrated that the slower rate of delivery $(>30 \mathrm{~h})$ was attributed to the presence of terminal amines interacting with the $-\mathrm{COOH}$ moiety present on cephalexin. Contrastingly, mesoporous silica spheres functionalised with terminal sulphonic acid led to a fast drug release rate $(<5 \mathrm{~h})$ due to a lack of interaction between cephalexin and the sulphonic acid, regardless of the amino moiety present on cephalexin. The extensive research in mesoporous aided drug-delivery displays the tremendous potential in individualised delivery methods for both specific drug molecules and treatments, with additional diagnostic capabilities if coupled with UCNPs.

Lastly, Jiang, S. et al. (2009) [73] demonstrate coated $\mathrm{NaYF}_{4}: \mathrm{Yb}^{3+}, \mathrm{Er}^{3+}$ UCNPs with $\mathrm{mSiO}_{2}$ for their use in the targeted delivery of small interfering RNA (siRNA) to cancer cells. The surface silanols groups exhibited by $\mathrm{mSiO}_{2}$ were used in a condensation reaction to couple $\mathrm{N}$-[3-(trimethoxysilyl)propyl]ethylenediamine (AEAPTMS) to the UCNPs. Following this, the newly affixed terminal amino groups were used to further functionalise the UCNPs with an Anti-Her2 antibody by reaction of its terminal amino group through carbodiimide chemistry. Addition of the antibody allowed for the targeting of surface Her2 receptors that are overexpressed on SK-BR-3 cells and was coupled to the UCNPs via carbodiimide chemistry. Subsequently, absorption of siRNA into the mesopores of the silica was achieved via incubation with the UCNPs in solution, after which the gene silencing effect of the siRNA was studied via an exogenous luciferase gene expression assay. Down-regulation of the luciferase gene expression was measured to be $45.5 \%$ whilst control samples did not illustrate any down-regulation of the expression, allowing for the successful realisation of a targeted siRNA delivery system. Furthermore, an MTT assay was used to assess the cytotoxicity and subsequent cell viability of SK-BR-3 cells, with cell viability being determined to be above $98.6 \%$ with a UCNP concentration less than $50 \mu \mathrm{g} \mathrm{mL}{ }^{-1}$, while a decrease to $92.5 \%$ when the concentration was increased to $80 \mu \mathrm{g} \mathrm{mL}^{-1}$ was observed.

\subsubsection{Thiol Moiety Modified UCNPs via Silanisation}

Thiol moieties tend to be the least common of the three base functionalisations for silica, perhaps mainly due to the large variety of biomolecules that exhibit terminal amino or carboxyl moieties, therefore allowing easy coupling to the same moieties due to the great extent of which the methodology surrounding carbodiimide chemistry has been covered. Thiols are particularly ideal for applications which involve a thiol-sensitive maleimide moiety that can be interacted with by thiol moieties present on the surface of UCNPS [72,76]. Table 6 summarised the surface modified UCNPs via silanisation with thiol moieties.

Table 6. Summary of the surface modified UCNPs via silanisation with thiol moieties.

\begin{tabular}{|c|c|c|c|c|c|}
\hline UCNP & $\begin{array}{l}\text { Silica } \\
\text { Type }\end{array}$ & $\begin{array}{c}\text { Functional } \\
\text { Moiety }\end{array}$ & Method & Application & Ref. \\
\hline $\mathrm{NaYF}_{4}: \mathrm{Yb}^{3+}, \mathrm{Tm}^{3+}$ & $\mathrm{dSiO}_{2}$ & Thiol & $\begin{array}{l}\text { Thiol-Maleimide } \\
\text { "Click" Chemistry }\end{array}$ & $\begin{array}{l}\text { Photocaged UCNPs for remotely } \\
\text { triggered cellular transduction }\end{array}$ & [76] \\
\hline $\begin{array}{l}\mathrm{NaYF}_{4}: \mathrm{Yb}^{3+} \\
\mathrm{Tm}^{3+} / \mathrm{Au}-\mathrm{NP}\end{array}$ & $\mathrm{dSiO}_{2}$ & Thiol & $\begin{array}{l}\text { Sulfur-Gold Bond } \\
\text { Interaction }\end{array}$ & $\begin{array}{l}\text { UCNPs with attenuated X-Ray } \\
\text { interaction as a theranostic platform }\end{array}$ & [77] \\
\hline
\end{tabular}

Work conducted by Gao et al. (2015) [76] saw the development of a photocaged upconversion based system that could allow for the remote triggering of intracellular signal transduction via the excitation of UCNPs (displayed in Figure 14). Specifically, $\mathrm{NaYF}_{4}: \mathrm{Yb}^{3+}, \mathrm{Tm}^{3+}$ were surface modified 
with a $\mathrm{dSiO}_{2}$ shell after which they were subsequently functionalised with terminal thiol groups via the addition of MPTMS. The thiol groups provide additional hydrophilicity to the nanoparticles (on top of the hydrophilicity imparted by the silica shell), thus affording them to be compatible with physiological medium as well as providing further functionality pathways. Following this, PEG3000 was grafted onto the $\mathrm{dSiO}_{2}$ surface through interaction of terminal thiol-sensitive maleimido groups exhibited by the PEG molecules with the newly affixed terminal thiol groups.

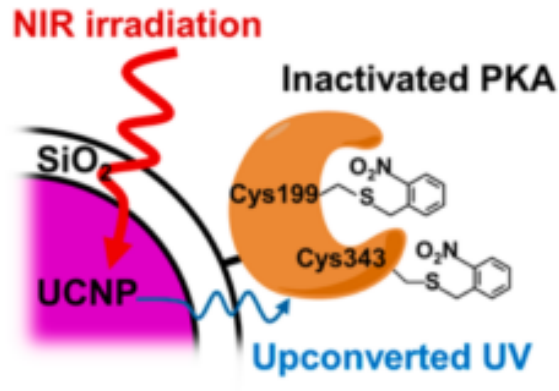

Caged PKAVUCNP

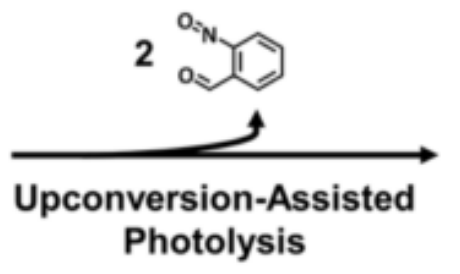

Photolysis

Figure 14. Caged PKA/UCNP complex design and the process of upconversion-assisted PKA uncaging. Reprinted with permission from [76]. Copyright 2015 American Chemical Society.

Further conjugation of previously prepared protein kinase A (PKA) and photocaged PKA to the UCNPs was undertaken, whereby the protein was immobilised via electrostatic interactions [78]. The activity of the PKA was determined by measuring the formation of NADH as a result of phosphorylation of the peptide after coupling with lactate dehydrogenase and pyruvate kinase, leading to oxidation. As PKA can unbundle and disintegrate stress fibres in cells, the group demonstrated that the caged PKA UCNPs caused no disintegration of stress fibres in REF52 cells, resolving that the UCNPs were enzymatically inert if they were not intentionally irradiated with UV or NIR light. Furthermore, disintegration of stress fibres was confirmed quantitatively through the staining intensities of nanoparticle regions relative to background stained stress fibres in the cells. This is a particularly interesting application of UCNPs as there have been minimal attempts at designing remotely-activated enzymatic systems in regards to upconversion.

The development of hybrid nanoparticles consisting of both lanthanide-doped UCNPs and gold (Au) nanoparticles was exhibited by Wang et al. (2011) [77], which displayed attenuated X-ray interaction. After synthesis of $\mathrm{NaYF}_{4}: \mathrm{Yb}^{3+}, \mathrm{Tm}^{3+} \mathrm{UCNPs}$, the group coated the particles with a $\mathrm{dSiO}_{2}$ shell followed by subsequent functionalisation via MPTMS to provide surface thiol moieties. Due to the particularly sturdy interaction exhibit between Au and thiolates, the citrate present on the as-synthesised Au-NPs can be replaced by the terminal thiol moieties present on the UCNP silica shell surface. Thus, mixing of the two nanoparticle solutions can lead to effective hybridization

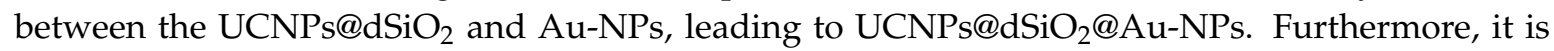
asserted that the thiolate ligands on the particles can aid in the prevention of particle agglomeration through steric driven repulsion, thus imparting greater colloidal stability when the particles are dispersed in aqueous solutions. As Au-NPs exhibit luminescent absorption near $\sim 541 \mathrm{~nm}$, they can be effectively used as an energy acceptor in a system whereby UCNPs act as energy donors via LRET mechanisms. This is due to a close overlap with upconversion emission exhibited by UCNPs at $\sim 541 \mathrm{~nm}$ and leads to the quenching of upconversion luminescence. However, it was determined

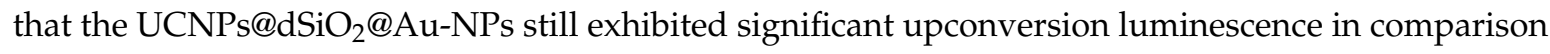
to unhybridised particles. Furthermore, it was demonstrated that the UCNPs@dSiO $\mathrm{d}_{2} @ \mathrm{Au}-\mathrm{NPs}$ had greater X-ray attenuation than unhybridised Au-NPs at the same concentration. This system can serve as a platform that can allow for the realisation of various diagnostic, as well as therapeutic applications due to the great multi-modal functionality it exhibits. 


\section{Conclusions}

There is a multitude of ways in which it is possible to approach the surface modification of UCNPs to provide various functional moieties for further use in applications such as biosensing, bioimaging, and drug delivery. As discussed, the primary base functionalities $\left(-\mathrm{COOH}, \mathrm{NH}_{2}\right.$ and -SH) can imparted onto the surfaces of UCNPs through techniques such as ligand exchange and silanisation. These functionalities can be used to coordinate ligands to the surfaces of UCNPs, as well as grant hydrophilic properties to the UCNPs for their use in aqueous mediums, which is a key objective for bio-applications. Moreover, the affixation of these functional moieties provides further capabilities such as bio-conjugation. Amino and carboxyl groups are evidently favoured modifications due to the extensive methodology surrounding carbodiimide chemistry, the popularity of which can be explained by the abundance of terminal carboxyl and amino groups on biomolecules. DNA and protein are common examples of such biomolecules that are actively conjugated to UCNPs for their use in various bio-applications and can be coupled to UCNPs via carbodiimide chemistry. Surface modifications themselves offer functionality, with silica for example providing encapsulation of the nanocore thereby protecting it from unwanted external stimuli. As a result, dissolution and desaturating of the particles are substantially decreased. Mesoporous silica and polymeric ligands can grant the ability to load therapeutic drug cargo or photosensitisers, an advantage over ligands which require external conjugation of drugs or biomolecules that may display unwanted interactions due to their placement on the surface of particles. Furthermore, it allows for complex design around the working mechanisms of the desired application, for example, separate functionalisation of $\mathrm{mSiO}_{2}$ pores to the surface can award greater control over mechanisms such as drug release times whilst maintaining the ability to specifically target and localise treatment. Although there only a few base functionalities, the way they are utilised in various applications can be extremely diverse given the necessary conditions for the operation. Manipulation of properties via $\mathrm{pH}$ changes, temperature and electrostatic characteristics, for example, can allow for these same functional moieties to be used differently and more effectively to achieve either similar or drastically different goals.

Author Contributions: The theme of the review was conceptualised by A.G. as well as the research, discussion, initial drafting and editing of content. Generation of the idea to write the review, organisation of structure and editing of content can be attributed to X.X. All authors contributed to revisions of the manuscript.

Funding: This research received no external funding.

Conflicts of Interest: The authors declare no conflict of interest.

\section{References}

1. Xie, J.; Lee, S.; Chen, X. Nanoparticle-based theranostic agents. Adv. Drug Deliv. Rev. 2010, 62, $1064-1079$. [CrossRef] [PubMed]

2. Chen, G.; Qiu, H.; Prasad, P.N.; Chen, X. Upconversion nanoparticles: Design, nanochemistry, and applications in Theranostics. Chem. Rev. 2014, 114, 5161-5214. [CrossRef] [PubMed]

3. Wang, F.; Banerjee, D.; Liu, Y.; Chen, X.; Liu, X. Upconversion nanoparticles in biological labeling, imaging, and therapy. Analyst 2010, 135, 1839. [CrossRef] [PubMed]

4. Biju, V. Chemical modifications and bioconjugate reactions of nanomaterials for sensing, imaging, drug delivery and therapy. Chem. Soc. Rev. 2014, 43, 744-764. [CrossRef] [PubMed]

5. Sedlmeier, A.; Gorris, H.H. Surface modification and characterization of photon-upconverting nanoparticles for bioanalytical applications. Chem. Soc. Rev. 2015, 44, 1526-1560. [CrossRef] [PubMed]

6. Treccani, L.; Yvonne Klein, T.; Meder, F.; Pardun, K.; Rezwan, K. Functionalized ceramics for biomedical, biotechnological and environmental applications. Acta Biomater. 2013, 9, 7115-7150. [CrossRef] [PubMed]

7. Zhang, F. Photon Upconversion Nanomaterials; Lockwood, D.J., Ed.; Nanostructure Science and Technology; Springer: Berlin/Heidelberg, Germany, 2015; ISBN 978-3-662-45596-8.

8. Thanh, N.T.K.; Green, L.A.W. Functionalisation of nanoparticles for biomedical applications. Nano Today 2010, 5, 213-230. [CrossRef] 
9. Wilhelm, S.; Kaiser, M.; Würth, C.; Heiland, J.; Carrillo-Carrion, C.; Muhr, V.; Wolfbeis, O.S.; Parak, W.J.; Resch-Genger, U.; Hirsch, T. Water dispersible upconverting nanoparticles: Effects of surface modification on their luminescence and colloidal stability. Nanoscale 2015, 7, 1403-1410. [CrossRef] [PubMed]

10. Duong, H.T.T.; Chen, Y.; Tawfik, S.A.; Wen, S.; Parviz, M.; Shimoni, O.; Jin, D. Systematic investigation of functional ligands for colloidal stable upconversion nanoparticles. RSC Adv. 2018, 8, 4842-4849. [CrossRef]

11. Wu, S.-H.; Hung, Y.; Mou, C.-Y. Mesoporous silica nanoparticles as nanocarriers. Chem. Commun. 2011, 47, 9972. [CrossRef] [PubMed]

12. Shan, J.; Yao, N.; Ju, Y. Ligand Effects and Synthesis of $\mathrm{NaYF}_{4}$ Based up and Downconversion Colloidal Nanophosphors. Fluor.-Relat. Nanosci. Energy Appl. 2011, 71-85. [CrossRef]

13. Liu, J.-N.; Bu, W.-B.; Shi, J.-L. Silica Coated Upconversion Nanoparticles: A Versatile Platform for the Development of Efficient Theranostics. Acc. Chem. Res. 2015, 48, 1797-1805. [CrossRef] [PubMed]

14. Bogdan, N.; Vetrone, F.; Capobianco, J.A. Synthesis of Ligand-Free Colloidally Stable Water Dispersible Brightly Luminescent Lanthanide-Doped Upconverting Nanoparticles. Nano Lett. 2011, 11, 835-840. [CrossRef] [PubMed]

15. Sedlmeier, A. Surface Modification and Scan Imaging of Upconverting Nanoparticles; University of Regensburg: Regensburg, Germany, 2015.

16. Jiang, S.; Win, K.Y.; Liu, S.; Teng, C.P.; Zheng, Y.; Han, M.-Y. Surface-functionalized nanoparticles for biosensing and imaging-guided therapeutics. Nanoscale 2013, 5, 3127. [CrossRef] [PubMed]

17. Liu, F.; Zhao, Q.; You, H.; Wang, Z. Synthesis of stable carboxy-terminated $\mathrm{NaYF}_{4}: \mathrm{Yb}^{3+}, \mathrm{Er}^{3+} @ \mathrm{SiO}_{2}$ nanoparticles with ultrathin shell for biolabeling applications. Nanoscale 2013, 5, 1047-1053. [CrossRef] [PubMed]

18. Wang, Y.; Liu, B. Silica nanoparticle assisted DNA assays for optical signal amplification of conjugated polymer based fluorescent sensors. Chem. Commun. 2007, 3553-3555. [CrossRef]

19. Li, L.L.; Wu, P.; Hwang, K.; Lu, Y. An exceptionally simple strategy for DNA-functionalized up-conversion nanoparticles as biocompatible agents for nanoassembly, DNA delivery, and imaging. J. Am. Chem. Soc. 2013, 135, 2411-2414. [CrossRef] [PubMed]

20. Alonso-Cristobal, P.; Vilela, P.; El-Sagheer, A.; Lopez-Cabarcos, E.; Brown, T.; Muskens, O.L.; Rubio-Retama, J.; Kanaras, A.G. Highly Sensitive DNA Sensor Based on Upconversion Nanoparticles and Graphene Oxide. ACS Appl. Mater. Interfaces 2015, 7, 12422-12429. [CrossRef] [PubMed]

21. Song, K.; Kong, X.; Liu, X.; Zhang, Y.; Zeng, Q.; Tu, L.; Shi, Z.; Zhang, H. Aptamer optical biosensor without bio-breakage using upconversion nanoparticles as donors. Chem. Commun. 2012, 48, 1156-1158. [CrossRef] [PubMed]

22. Mendez-Gonzalez, D.; Laurenti, M.; Latorre, A.; Somoza, A.; Vazquez, A.; Negredo, A.I.; López-Cabarcos, E.; Calderón, O.G.; Melle, S.; Rubio-Retama, J. Oligonucleotide Sensor Based on Selective Capture of Upconversion Nanoparticles Triggered by Target-Induced DNA Interstrand Ligand Reaction. ACS Appl. Mater. Interfaces 2017, 9, 12272-12281. [CrossRef] [PubMed]

23. Wang, H.; Yang, R.R.; Yang, L.; Tan, W. Nucleic Acid Conjugated Nanomaterials for Enhanced Molecular Recognition. ACS Nano 2009, 3, 2451-2460. [CrossRef] [PubMed]

24. Liu, J.; Bu, W.; Pan, L.; Shi, J. NIR-Triggered Anticancer Drug Delivery by Upconverting Nanoparticles with Integrated Azobenzene-Modified Mesoporous Silica. Angew. Chem. Int. Ed. 2013, 52, 4375-4379. [CrossRef] [PubMed]

25. Fedoryshin, L.L. Near-Infrared Triggered Anti-Cancer Drug Release from Upconverting Nanoparticles. ACS Appl. Mater. Interfaces 2014, 6, 13600-13606. [CrossRef] [PubMed]

26. Huang, Y.; Hemmer, E.; Rosei, F.; Vetrone, F. Multifunctional Liposome Nanocarriers Combining Upconverting Nanoparticles and Anticancer Drugs. J. Phys. Chem. B 2016, 120, 4992-5001. [CrossRef] [PubMed]

27. Li, N.; Wen, X.; Liu, J.; Wang, B.; Zhan, Q.; He, S. Yb ${ }^{3+}$-enhanced UCNP@SiO ${ }_{2}$ nanocomposites for consecutive imaging, photothermal-controlled drug delivery and cancer therapy. Opt. Mater. Express 2016, 6, 1161. [CrossRef]

28. Chen, J.; Zhao, J.X. Upconversion nanomaterials: Synthesis, mechanism, and applications in sensing. Sensors 2012, 12, 2414-2435. [CrossRef] [PubMed]

29. Ang, L.Y.; Lim, M.E.; Ong, L.C.; Zhang, Y. Applications of upconversion nanoparticles in imaging, detection and therapy. Nanomedicine 2011, 6, 1273-1288. [CrossRef] [PubMed] 
30. Li, L.L.; Zhang, R.; Yin, L.; Zheng, K.; Qin, W.; Selvin, P.R.; Lu, Y. Biomimetic surface engineering of lanthanide-doped upconversion nanoparticles as versatile bioprobes. Angew. Chem. Int. Ed. 2012, 51, 6121-6125. [CrossRef] [PubMed]

31. Chen, Y.; Duong, H.T.T.; Wen, S.; Mi, C.; Zhou, Y.; Shimoni, O.; Valenzuela, S.M.; Jin, D. Exonuclease III-Assisted Upconversion Resonance Energy Transfer in a Wash-Free Suspension DNA Assay. Anal. Chem. 2018, 90, 663-668. [CrossRef] [PubMed]

32. Wang, L.L.; Yan, R.; Huo, Z.; Wang, L.L.; Zeng, J.; Bao, J.; Wang, X.; Peng, Q.; Li, Y. Fluorescence resonant energy transfer biosensor based on upconversion-luminescent nanoparticles. Angew. Chem. Int. Ed. 2005, 44, 6054-6057. [CrossRef] [PubMed]

33. Cheng, L.; Yang, K.; Shao, M.; Lee, S.T.; Liu, Z. Multicolor in vivo imaging of upconversion nanoparticles with emissions tuned by luminescence resonance energy transfer. J. Phys. Chem. C 2011, 115, 2686-2692. [CrossRef]

34. Montalti, M.; Prodi, L.; Rampazzo, E.; Zaccheroni, N. Dye-doped silica nanoparticles as luminescent organized systems for nanomedicine. Chem. Soc. Rev. 2014, 43, 4243-4268. [CrossRef] [PubMed]

35. Fedoryshin, L.L. Near-Infrared Triggered Anti-Cancer Drug Release from Upconverting Nanoparticles; University of Toronto: Toronto, ON, Canada, 2014.

36. An, Y.; Chen, M.; Xue, Q.; Liu, W. Preparation and self-assembly of carboxylic acid-functionalized silica. J. Colloid Interface Sci. 2007, 311, 507-513. [CrossRef] [PubMed]

37. Cashin, V.B.; Eldridge, D.S.; Yu, A.; Zhao, D. Surface functionalization and manipulation of mesoporous silica adsorbents for improved removal of pollutants: A review. Environ. Sci. Water Res. Technol. 2018, 4, 110-128. [CrossRef]

38. Perez, R.A.; Singh, R.K.; Kim, T.-H.; Kim, H.-W. Silica-based multifunctional nanodelivery systems toward regenerative medicine. Mater. Horiz. 2017, 4, 772-799. [CrossRef]

39. Alberti, S.; Soler-Illia, G.J.A.A.; Azzaroni, O. Gated supramolecular chemistry in hybrid mesoporous silica nanoarchitectures: Controlled delivery and molecular transport in response to chemical, physical and biological stimuli. Chem. Commun. 2015, 51, 6050-6075. [CrossRef] [PubMed]

40. Muhr, V.; Wilhelm, S.; Hirsch, T.; Wolfbeis, O.S. Upconversion Nanoparticles: From Hydrophobic to Hydrophilic Surfaces. Acc. Chem. Res. 2014, 47, 3481-3493. [CrossRef] [PubMed]

41. Chen, Z.; Chen, H.; Hu, H.; Yu, M.; Li, F. Versatile Synthesis Strategy for Carboxylic Acid—Functionalized Upconverting Nanophosphors as Biological Labels Versatile Synthesis Strategy for Carboxylic Biological Labels. J. Am. Chem. Soc. 2008, 130, 3023-3029. [CrossRef] [PubMed]

42. Deng, R.; Xie, X.; Vendrell, M.; Chang, Y.-T.; Liu, X. Intracellular Glutathione Detection Using $\mathrm{MnO}_{2}-$ Nanosheet-Modified Upconversion Nanoparticles. J. Am. Chem. Soc. 2011, 133, 20168-20171. [CrossRef] [PubMed]

43. Naccache, R.; Vetrone, F.; Mahalingam, V.; Cuccia, L.A.; Capobianco, J.A. Controlled Synthesis and Water Dispersibility of Hexagonal Phase $\mathrm{NaGdF}^{4}: \mathrm{Ho}^{3+} / \mathrm{Yb}^{3+}$ Nanoparticles. Chem. Mater. 2009, 21, 717-723. [CrossRef]

44. Chen, C.; Li, C.; Shi, Z. Current Advances in Lanthanide-Doped Upconversion Nanostructures for Detection and Bioapplication. Adv. Sci. 2016, 3. [CrossRef] [PubMed]

45. Boyer, J.C.; Manseau, M.P.; Murray, J.I.; Van Veggel, F.C.J.M. Surface modification of upconverting NaYF4nanoparticles with PEG-phosphate ligands for NIR $(800 \mathrm{~nm})$ biolabeling within the biological window. Langmuir 2010, 26, 1157-1164. [CrossRef] [PubMed]

46. Meiser, F.; Cortez, C.; Caruso, F. Biofunctionalization of Fluorescent Rare-Earth-Doped Lanthanum Phosphate Colloidal Nanoparticles. Angew. Chem. Int. Ed. 2004, 43, 5954-5957. [CrossRef] [PubMed]

47. Liu, C.; Wang, H.; Li, X.; Chen, D. Monodisperse, size-tunable and highly efficient $\beta-N a Y F 4: \operatorname{Yb}, \operatorname{Er}(\operatorname{Tm})$ up-conversion luminescent nanospheres: Controllable synthesis and their surface modifications. J. Mater. Chem. 2009, 19, 3546. [CrossRef]

48. Traina, C.A.; Schwartz, J. Surface Modification of $\mathrm{Y}_{2} \mathrm{O}_{3}$ Nanoparticles. Langmuir 2007, $23,9158-9161$. [CrossRef] [PubMed]

49. Shen, J.; Sun, L.D.; Zhang, Y.W.; Yan, C.H. Superparamagnetic and upconversion emitting $\mathrm{Fe}_{3} \mathrm{O}_{4} / \mathrm{NaYF}_{4}: \mathrm{Yb}_{\text {, }}$ Er hetero-nanoparticles via a crosslinker anchoring strategy. Chem. Commun. 2010, 46, 5731-5733. [CrossRef] [PubMed] 
50. Zhang, Q.; Song, K.; Zhao, J.; Kong, X.; Sun, Y.; Liu, X.; Zhang, Y.; Zeng, Q.; Zhang, H. Hexanedioic acid mediated surface-ligand-exchange process for transferring $\mathrm{NaYF}_{4}: \mathrm{Yb} / \mathrm{Er}$ (or $\mathrm{Yb} / \mathrm{Tm}$ ) up-converting nanoparticles from hydrophobic to hydrophilic. J. Colloid Interface Sci. 2009, 336, 171-175. [CrossRef] [PubMed]

51. Kumar, M.; Zhang, P. Highly sensitive and selective label-free optical detection of mercuric ions using photon upconverting nanoparticles. Biosens. Bioelectron. 2010, 25, 2431-2435. [CrossRef] [PubMed]

52. Kumar, M.; Zhang, P. Highly Sensitive and Selective Label-Free Optical Detection of DNA Hybridization Based on Photon Upconverting Nanoparticles. Langmuir 2009, 25, 6024-6027. [CrossRef] [PubMed]

53. Wang, P.; Zhang, P. Ligase-assisted, upconversion luminescence resonance energy transfer-based method for specific and sensitive detection of V600E mutation in the BRAF gene. RSC Adv. 2014, 4, 56235-56240. [CrossRef]

54. Cui, S.; Chen, H.; Zhu, H.; Tian, J.; Chi, X.; Qian, Z.; Achilefu, S.; Gu, Y. Amphiphilic chitosan modified upconversion nanoparticles for in vivo photodynamic therapy induced by near-infrared light. J. Mater. Chem. 2012, 22, 4861-4873. [CrossRef]

55. Liebherr, R.B.; Soukka, T.; Wolfbeis, O.S.; Gorris, H.H. Maleimide activation of photon upconverting nanoparticles for bioconjugation. Nanotechnology 2012, 23. [CrossRef] [PubMed]

56. Jia, X.; Yin, J.; He, D.; He, X.; Wang, K.; Chen, M.; Li, Y. Polyacrylic acid modified upconversion nanoparticles for simultaneous pH-triggered drug delivery and release imaging. J. Biomed. Nanotechnol. 2013, 9, $2063-2072$. [CrossRef] [PubMed]

57. Qian, H.S.; Guo, H.C.; Ho, P.C.L.; Mahendran, R.; Zhang, Y. Mesoporous-silica-coated up-conversion fluorescent nanoparticles for photodynamic therapy. Small 2009, 5, 2285-2290. [CrossRef] [PubMed]

58. Doughan, S.; Han, Y.; Uddayasankar, U.; Krull, U.J. Solid-phase covalent immobilization of upconverting nanoparticles for biosensing by luminescence resonance energy transfer. ACS Appl. Mater. Interfaces 2014, 6, 14061-14068. [CrossRef] [PubMed]

59. Bogdan, N.; Vetrone, F.; Roy, R.; Capobianco, J.A. Carbohydrate-coated lanthanide-doped upconverting nanoparticles for lectin recognition. J. Mater. Chem. 2010, 20, 7543-7550. [CrossRef]

60. Dong, B.; Xu, S.; Sun, J.; Bi, S.; Li, D.; Bai, X.; Wang, Y.; Wang, L.; Song, H. Multifunctional NaYF $\mathrm{YF}^{4} \mathrm{Yb}^{3+}$, $\mathrm{Er}^{3+} @ \mathrm{Ag}$ core/shell nanocomposites: Integration of upconversion imaging and photothermal therapy. J. Mater. Chem. 2011, 21, 6193. [CrossRef]

61. Chen, D.; Yu, Y.; Huang, F.; Lin, H.; Huang, P.; Yang, A.; Wang, Z.; Wang, Y. Lanthanide dopant-induced formation of uniform sub-10 $\mathrm{nm}$ active-core/active-shell nanocrystals with near-infrared to near-infrared dual-modal luminescence. J. Mater. Chem. 2012, 22, 2632-2640. [CrossRef]

62. Kumar, R.; Nyk, M.; Ohulchanskyy, T.Y.; Flask, C.A.; Prasad, P.N. Combined optical and MR bloimaging using rare earth ion doped NaYF4nanocrystals. Adv. Funct. Mater. 2009, 19, 853-859. [CrossRef]

63. Kumar, R.; Roy, I.; Ohulchanskyy, T.Y.; Goswami, L.N.; Bonoiu, A.C.; Bergey, E.J.; Tramposch, K.M.; Maitra, A.; Prasad, P.N. Covalently Dye-Linked, Surface-Controlled, and Bioconjugated Organically Modified Silica Nanoparticles as Targeted Probes for Optical Imaging. ACS Nano 2008, 2, 449-456. [CrossRef] [PubMed]

64. Ji, T.; Xinqiang, X.; Dong, X.; Zhou, Q.; Chen, G. Monodisperse Water-Stable $\mathrm{SiO}_{2}$-Coated Fluoride Upconversion Nanoparticles with Tunable Shell Thickness. Int. J. Nanomater. Nanotechnol. Nanomed. 2017, 3, 15-18. [CrossRef]

65. Xu, F.; Hu, M.; Liu, C.; Choi, S.K. Yolk-structured multifunctional up-conversion nanoparticles for synergistic photodynamic-sonodynamic antibacterial resistance therapy. Biomater. Sci. 2017, 5, 678-685. [CrossRef] [PubMed]

66. Sinha, A.; Chakraborty, A.; Jana, N.R. Dextran-gated, multifunctional mesoporous nanoparticle for glucose-responsive and targeted drug delivery. ACS Appl. Mater. Interfaces 2014, 6, 22183-22191. [CrossRef] [PubMed]

67. He, M.; Pang, X.; Liu, X.; Jiang, B.; He, Y.; Snaith, H.; Lin, Z. Monodisperse Dual-Functional Upconversion Nanoparticles Enabled Near-Infrared Organolead Halide Perovskite Solar Cells. Angew. Chem. Int. Ed. 2016, 55, 4280-4284. [CrossRef] [PubMed]

68. Cash, B.M.; Wang, L.; Benicewicz, B.C. The preparation and characterization of carboxylic acid-coated silica nanoparticles. J. Polym. Sci. Part A Polym. Chem. 2012, 50, 2533-2540. [CrossRef]

69. Maria Claesson, E.; Philipse, A.P. Thiol-functionalized silica colloids, grains, and membranes for irreversible adsorption of metal(oxide) nanoparticles. Colloids Surf. A Physicochem. Eng. Asp. 2007, 297, 46-54. [CrossRef] 
70. Hlaváček, A.; Sedlmeier, A.; Skládal, P.; Gorris, H.H. Electrophoretic characterization and purification of silica-coated photon-upconverting nanoparticles and their bioconjugates. ACS Appl. Mater. Interfaces 2014, 6, 6930-6935. [CrossRef] [PubMed]

71. Zhang, J.; Liu, F.; Li, T.; He, X.; Wang, Z. Surface charge effect on the cellular interaction and cytotoxicity of $\mathrm{NaYF}_{4}: \mathrm{Yb}^{3+}, \mathrm{Er}^{3+} @ \mathrm{SiO}_{2}$ nanoparticles. RSC Adv. 2014, 5, 7773-7780. [CrossRef]

72. Chien, Y.H.; Chou, Y.L.; Wang, S.W.; Hung, S.T.; Liau, M.C.; Chao, Y.J.; Su, C.H.; Yeh, C.S. Near-infrared light photocontrolled targeting, bioimaging, and chemotherapy with caged upconversion nanoparticles in vitro and in vivo. ACS Nano 2013, 7, 8516-8528. [CrossRef] [PubMed]

73. Jiang, S.; Zhang, Y.; Lim, K.M.; Sim, E.K.W.; Ye, L. NIR-to-visible upconversion nanoparticles for fluorescent labeling and targeted delivery of siRNA. Nanotechnology 2009, 20, 155101. [CrossRef] [PubMed]

74. Manzano, M.; Aina, V.; Areán, C.O.; Balas, F.; Cauda, V.; Colilla, M.; Delgado, M.R.; Vallet-Regí, M. Studies on MCM-41 mesoporous silica for drug delivery: Effect of particle morphology and amine functionalization. Chem. Eng. J. 2008, 137, 30-37. [CrossRef]

75. Basaldella, E.I.; Legnoverde, M.S. Functionalized silica matrices for controlled delivery of cephalexin. J. Sol-Gel Sci. Technol. 2010, 56, 191-196. [CrossRef]

76. Gao, H. De; Thanasekaran, P.; Chiang, C.W.; Hong, J.L.; Liu, Y.C.; Chang, Y.H.; Lee, H.M. Construction of a Near-Infrared-Activatable Enzyme Platform to Remotely Trigger Intracellular Signal Transduction Using an Upconversion Nanoparticle. ACS Nano 2015, 9, 7041-7051. [CrossRef] [PubMed]

77. Wang, Z.; Wu, L.; Liang, H.; Cai, W.; Zhang, Z.; Jiang, Z. Controllable synthesis of bifunctional $\mathrm{NaYF}_{4}: \mathrm{Yb}^{3+} / \mathrm{Ho}^{3+} @ \mathrm{SiO}_{2} / \mathrm{Au}$ nanoparticles with upconversion luminescence and high X-ray attenuation. J. Alloy. Compd. 2011, 509, 9144-9149. [CrossRef]

78. Gibson, R.M.; Ji-Buechler, Y.; Taylor, S.S. Identification of electrostatic interaction sites between the regulatory and catalytic subunits of cyclic AMP-dependent protein kinase. Protein Sci. 1997, 6, 1825-1834. [CrossRef] [PubMed]

(C) 2018 by the authors. Licensee MDPI, Basel, Switzerland. This article is an open access article distributed under the terms and conditions of the Creative Commons Attribution (CC BY) license (http:/ / creativecommons.org/licenses/by/4.0/). 